\title{
Review: current international research into cellulose nanofibres and nanocomposites
}

\author{
S. J. Eichhorn - A. Dufresne - M. Aranguren - N. E. Marcovich · \\ J. R. Capadona - S. J. Rowan - C. Weder - W. Thielemans - M. Roman · \\ S. Renneckar $\cdot$ W. Gindl $\cdot$ S. Veigel $\cdot$ J. Keckes $\cdot$ H. Yano $\cdot$ K. Abe $\cdot$ \\ M. Nogi - A. N. Nakagaito - A. Mangalam - J. Simonsen · A. S. Benight · \\ A. Bismarck $\cdot$ L. A. Berglund $\cdot$ T. Peijs
}

\begin{abstract}
This paper provides an overview of recent progress made in the area of cellulose nanofibre-based nanocomposites. An introduction into the methods used to isolate cellulose nanofibres (nanowhiskers, nanofibrils) is given, with details of their structure. Following this, the article is split into sections dealing with processing and characterisation of cellulose nanocomposites and new developments in the area, with particular emphasis on applications. The types of cellulose nanofibres covered are those extracted from plants by acid hydrolysis
\end{abstract}

\section{S. J. Eichhorn ( $\square)$}

Materials Science Centre, School of Materials and the Northwest Composites Centre, Grosvenor Street, Manchester M1 7HS, UK e-mail: stephen.j.eichhorn@manchester.ac.uk

\section{A. Dufresne \\ Grenoble Institute of Technology, The International School of Paper, Print Media \& Biomaterials (Grenoble INP Pagora), BP65, 38402 Saint Martin D'Hères Cedex, France}

M. Aranguren - N. E. Marcovich

National Institute of Research in Science and Technology of Materials (INTEMA), Universidad Nacional de Mar del Plata, Av. Juan B. Justo 4302, B7608FDQ Mar del Plata, Argentina

\section{J. R. Capadona}

Rehabilitation Research and Development, Louis Stokes Cleveland DVA Medical Center, 10701 East Blvd., Cleveland, OH 44106, USA

\section{S. J. Rowan}

Department of Macromolecular Science and Engineering, Case Western Reserve University (CWRU), 2100 Adelbert Road, Cleveland, OH 44106, USA

\section{Weder} Adolphe Merkle Institute, University of Fribourg, 1700 Fribourg, Switzerland (nanowhiskers), mechanical treatment and those that occur naturally (tunicate nanowhiskers) or under culturing conditions (bacterial cellulose nanofibrils). Research highlighted in the article are the use of cellulose nanowhiskers for shape memory nanocomposites, analysis of the interfacial properties of cellulose nanowhisker and nanofibrilbased composites using Raman spectroscopy, switchable interfaces that mimic sea cucumbers, polymerisation from the surface of cellulose nanowhiskers by atom transfer radical polymerisation and ring opening polymerisation,

W. Thielemans

School of Chemistry and Process and Environmental Research Division, Faculty of Engineering, The University of Nottingham, Nottingham NG7 2RD, UK

M. Roman · S. Renneckar

Department of Wood Science and Forest Products, Virginia

Tech, 230 Cheatham Hall, 0323, Blacksburg, VA 24061, USA

W. Gindl

Department of Materials Science and Process Engineering, University of Natural Resources and Applied Life Sciences, BOKU-Vienna, Austria

\section{S. Veigel}

Wood K plus, Competence Centre for Wood Composites and Wood Chemistry, Linz, Austria

\section{J. Keckes}

Department of Materials Physics, Erich Schmid Institute of Materials Science, Austrian Academy of Sciences, University of Leoben, Leoben, Austria

H. Yano $\cdot$ K. Abe $\cdot$ M. Nogi $\cdot$ A. N. Nakagaito Research Institute for Sustainable Humanosphere, Kyoto University, Uji, Kyoto 611-0011, Japan 
and methods to analyse the dispersion of nanowhiskers. The applications and new advances covered in this review are the use of cellulose nanofibres to reinforce adhesives, to make optically transparent paper for electronic displays, to create DNA-hybrid materials, to generate hierarchical composites and for use in foams, aerogels and starch nanocomposites and the use of all-cellulose nanocomposites for enhanced coupling between matrix and fibre. A comprehensive coverage of the literature is given and some suggestions on where the field is likely to advance in the future are discussed.

\section{Introduction to cellulose structure/property relationships}

Cellulose is probably one of the most ubiquitous and abundant polymers on the planet, given its widespread industrial use in the present age, but also in the past for ropes, sails, paper, timber for housing and many other applications. By far the most commercially exploited natural resource containing cellulose is wood. The word 'material' in fact derives from the Latin for 'trunk of tree'. Indeed, Chaucer writes in the 'Parson's Tale' in 1390

"For he that is in helle hath defaute of light material. for certes, the derke light that shal

Come out of the fyr that evere shal brenne"

showing quite clearly that the relationship between wood and material was persisting into the Middle Ages.

\footnotetext{
A. Mangalam

Department of Wood Science and Forest Products,

Virginia Tech, 248 Cheatham Hall, Blacksburg, VA 24061, USA

J. Simonsen

Department of Wood Science \& Engineering, Oregon State University, Corvallis, OR 97331, USA

\section{A. S. Benight}

Departments of Chemistry \& Physics, Portland State University, Portland, OR, USA
}

\begin{abstract}
A. Bismarck
Department of Chemical Engineering, Polymer and Composite Engineering Group (PACE), Imperial College London, London, UK
\end{abstract}

L. A. Berglund

Department of Fibre \& Polymer Technology, Wallenberg Wood

Science Centre, KTH, 10044 Stockholm, Sweden

T. Peijs

Centre for Materials Research, Queen Mary, University

of London, Mile End Road, London E1 4NS, UK
Other plants also contain a large amount of cellulose, including hemp, flax, jute, ramie and cotton. In addition to these, there are non-plant sources of cellulose; for instance, forms produced by bacteria and cellulose produced by tunicates. Bacterial cellulose (BC) is produced by the gramnegative bacteria Acetobacter xylinum (or Gluconacetobacter xylinum), which manifests itself under special culturing conditions as a fine fibrous network of fibres [1]. Tunicate cellulose is produced by sea creatures (e.g. Microcosmus fulcatus) in the form of rod-like near perfect crystals of the material [2].

Since cellulose is classed as a carbohydrate (a substance containing carbon, hydrogen and oxygen), it is necessary to point out that although this term applies to a large number of organic compounds, cellulose is unique in that it can be either synthesised from, or hydrolysed to, monosaccharides [3]. The repeat unit of the cellulose polymer is known to comprise two anhydroglucose rings joined via a $\beta-1,4$ glycosidic linkage from this unit [4] (called cellobiose) as shown in Fig. 1. In its native form cellulose is typically called cellulose-I. This cellulose-I crystal form, or native cellulose, also comprises two allomorphs, namely cellulose $\mathrm{I} \alpha$ and $\mathrm{I} \beta$ [5]. The ratio of these allomorphs is found to vary from plant species to species, but bacterial and tunicate forms are $\mathrm{I} \alpha$ and $\mathrm{I} \beta$ rich, respectively [6, 7]. The crystal structures of cellulose allomorphs $\mathrm{I} \alpha$ and $\mathrm{I} \beta$ have been determined with great accuracy, particularly the complex hydrogen bonding system [6, 7]. The hydrogen bond network makes cellulose a relatively stable polymer, which does not readily dissolve in typical aqueous solvents and has no melting point. This network also gives the cellulose chains a high axial stiffness [8]. Since high stiffness is a desirable property for a reinforcement fibre in a composite, the determination of the crystal modulus of cellulose will be reviewed later.

Cellulose chains aggregate into the repeated crystalline structure to form microfibrils in the plant cell wall, which also aggregate into larger macroscopic fibres. It is this hierarchical structure that is essentially deconstructed in order to generate cellulose nanofibres from plants. $\mathrm{BC}$ and whiskers produced by tunicates already exist in

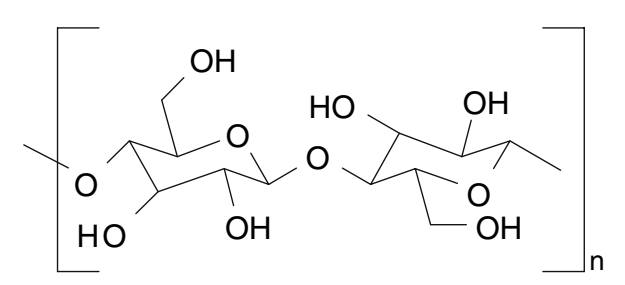

Fig. 1 The repeat unit of cellulose 
this form, making them desirable materials for niche applications.

The study of cellulosic nanofibres as a reinforcing phase in nanocomposites started 15 years ago [2]. Since then a huge amount of literature has been devoted to cellulose nanofibres, and it is becoming an increasingly topical subject. Different descriptors of these nanofibres are often referred to in the literature. These include "nanowhiskers" (or just simply "whiskers"), "nanocrystals" or even "monocrystals". These crystallites have also often been referred to in literature as "microfibrils", "microcrystals" or "microcrystallites", despite their nanoscale dimensions. The term "whiskers" is used to designate elongated crystalline rod-like nanoparticles, whereas the designation "nanofibrils" should be used to designate long flexible nanoparticles consisting of alternating crystalline and amorphous strings. ${ }^{1}$

In essence, the principle reason to utilise cellulose nanofibres in composite materials is because one can potentially exploit the high stiffness of the cellulose crystal for reinforcement. This can be done by breaking down the hierarchical structure of the plant into individualised nanofibres of high crystallinity, therefore reducing the amount of amorphous material present. Since plant fibres are hierarchically fibrous it is possible to do this, yielding a fibrous form of the material (nanowhiskers, nanofibrils), which due to their aspect ratio (length/ diameter) and therefore reinforcing capabilities are potentially suitable for composite materials. A high aspect ratio to the fibres is desirable as this enables a critical length for stress transfer from the matrix to the reinforcing phase. This will be discussed in more detail once the mechanical properties of cellulose nanofibres have been presented.

It is however not clear what the true crystal modulus of cellulose is, nor whether this stiffness is really obtainable from plants, bacteria or tunicates. Establishing a true value of the crystal modulus of cellulose sets an upper limit to what is achievable in terms of reinforcing potential.

The crystal modulus of cellulose was first determined in 1936 by Meyer and Lotmar [9] using a theoretical model and bond stiffness constants derived from spectroscopic measurements. They obtained a value of $\sim 120$ $\mathrm{GPa}$, which is close to values that were later

\footnotetext{
$\overline{1}$ For the sake of clarity and consistency the term "nanowhiskers" will be used to describe material hydrolysed from plants, and "nanofibrils" for material extracted by mechanical means or from native sources such as bacterial cellulose. The term "nanofibres" will be used as a general descriptor of both these sub-forms of reinforcement.
}

experimentally confirmed for this property [10, 11]. Despite this prediction, Meyer and Lotmar used an incorrect structure for cellulose, and so when this was corrected by Lyons, and a value of $180 \mathrm{GPa}$ was obtained [12]. Lyons however used an incorrect term in his mathematical expression for bond angle bending. This was rectified by Treloar [13], who reported a modulus of $56 \mathrm{GPa}$. This value is now considered to be too low, probably due to the lack of intramolecular hydrogen bonding in Treloar's cellulose structure [13]. Sakurada et al. [10] reported a value of $138 \mathrm{GPa}$ for the crystal modulus of cellulose, which was determined using X-ray diffraction of deformed fibre bundles. This paved the way for many more measurements and determinations of the crystal modulus of cellulose using X-ray diffraction [11, 14] and theoretical approaches [15-18], all of which have obtained values in the range 100-160 GPa. A more recent determination of the cellulose crystal modulus using inelastic X-ray scattering (IXS) reported a value of 220 GPa [19]. Such a high crystal modulus for cellulose has not been reported before, but this may be due to the fact that the assumption of uniform stress in the crystals of cellulose, a basic assumption for most crystal modulus determinations, is not correct $[19,20]$. This high value for the crystal modulus does however call into question theoretical approaches, and since they are consistent with experiment it may be that a more modest value is appropriate. Nevertheless, this value of the modulus of crystalline cellulose is quite large compared to other materials, especially if its comparatively lower density is taken into account. The moduli of a number of commonly used engineering materials are reported in Table 1. Also reported are the specific moduli (modulus/density), which show that the specific modulus of crystalline cellulose exceeds engineering materials such as steel, concrete, glass and aluminium. It is worth pointing out that cellulose has obvious disadvantages compared to traditional engineering materials; for instance, moisture absorption and swelling, and enzymatic degradability to name but two. It is worth pointing out that the microfibrils comprising plants do not swell themselves, as it is not energetically favourable for water to penetrate the bulk material.

Table 1 Moduli of engineering materials compared to cellulose

\begin{tabular}{lclll}
\hline Material & $\begin{array}{l}\text { Modulus } \\
(\mathrm{GPa})\end{array}$ & $\begin{array}{l}\text { Density } \\
\left(\mathrm{Mg} \mathrm{m}^{-3}\right)\end{array}$ & $\begin{array}{l}\text { Specific modulus } \\
\left(\mathrm{GPa} \mathrm{Mg}^{-1} \mathrm{~m}^{3}\right)\end{array}$ & Reference \\
\hline Aluminium & 69 & 2.7 & 26 & {$[279]$} \\
Steel & 200 & 7.8 & 26 & {$[279]$} \\
Glass & 69 & 2.5 & 28 & {$[279]$} \\
$\begin{array}{l}\text { Crystalline } \\
\text { cellulose }\end{array}$ & 138 & 1.5 & 92 & {$[10]$} \\
\hline
\end{tabular}


Table 2 Mechanical properties of some common plant fibres, namely, Young's modulus, specific Young's modulus, breaking strength and breaking strain

\begin{tabular}{lllll}
\hline Fibre type & $\begin{array}{l}\text { Young's } \\
\text { modulus } \\
(\mathrm{GPa})\end{array}$ & $\begin{array}{l}\text { Specific Young's } \\
\text { modulus } \\
\left(\mathrm{GPa} \mathrm{Mg}^{-1} \mathrm{~m}^{3}\right)\end{array}$ & $\begin{array}{l}\text { Breaking } \\
\text { strength } \\
(\mathrm{GPa})\end{array}$ & $\begin{array}{l}\text { Breaking } \\
\text { strain }(\%)\end{array}$ \\
\hline Flax & 27.0 & 18.0 & 0.81 & 3.0 \\
Jute & 25.8 & 17.2 & 0.47 & 1.8 \\
Hemp & 32.6 & 21.7 & 0.71 & 2.2 \\
Ramie & 21.9 & 14.6 & 0.89 & 3.7 \\
\hline
\end{tabular}

Data taken from Morton and Hearle [280] with the conversion from $\mathrm{N}$ tex ${ }^{-1}$ to GPa being made using a density of cellulose of $1.5 \mathrm{Mg} \mathrm{m}^{-3}$ from Table 1

The crystalline modulus of cellulose is hard to achieve in reality for a micron-sized fibre. Plant fibres often have moduli well below the crystalline value. Typical values of the modulus of a range of cellulose fibres are given in Table 2. When the density of the fibres is taken into account and specific modulus is determined (assuming a density of cellulose of $1.5 \mathrm{Mg} \mathrm{m}^{-3}$ ), then the values approach those of glass and other engineering solids. Many authors have published values for the modulus of plant fibres, some closer to the crystal modulus of cellulose quoted in Table 1. It is however difficult to obtain an accurate modulus for plant fibres, given their often irregular and variable cross-sections and the presence of voids in the form of lumens. It is beyond the scope of this article to fully review this aspect of natural fibre mechanics, but it is acknowledged that higher values than those quoted in Table 2 have been reported. Plant fibres are known to have variable mechanical properties, and another reason for extracting nanofibers and nanofibrils from the cell wall of plants is that they are thought to have more consistent properties.

One way therefore to obtain fibres that have a modulus that approaches that of pure crystalline cellulose is to break down the structure of the plant into the elementary nanofibrils, or crystals (nanowhiskers), that make up the fibre. Another approach is to source material that already has these structural forms. Two examples of this latter approach are to use microbial or BC, or to take whiskers of cellulose from an animal source (such as tunicates, a sea creature). BC fibrils are produced by a family of bacteria referred to as G. xylinum, under special culturing conditions [21]. The fibrils are generally in the form of a fine non-woven mesh or network, and have been reported to have moduli in the range $78-114 \mathrm{GPa}[22,23]$. Some of the first reports of the use of $\mathrm{BC}$ for composite materials appeared in the mid-1990s [24, 25], but there has recently been a resurgence of this research area. Notable examples of this come from Japan at Kyoto University [26] and from the UK at Imperial College [27-30], both of whom have contributed to this article.

Microfibrillated cellulose (MFC), where fine nano-sized fibrils are extracted from plants by mechanical processing and/or homogenisation, was first reported in the early 1980s [31]. Since then, and in more recent times, a large number of papers have been published on this topic, the full scope of which is beyond this review although an overview of the physical properties of nanofibrils from this source will be given in the section "An overview of cellulose whisker and nanofibre properties (Grenoble Institute of Technology (INPG), International School of Paper, Grenoble, France)". Notable recent examples of research into these materials have been by groups in Japan at Kyoto University [32], in Sweden at KTH [33], in the USA at Virginia Tech [34], and in Austria at BOKU, all of whom have made contributions to this article.

The existence of highly crystalline cellulose nanowhiskers has been known for some time. They can be extracted from plant material via a controlled acid hydrolysis, which more readily hydrolyses the amorphous regions of the cellulose, leaving high aspect ratio (length to diameter ratio) crystals of pure cellulose. The first report of cellulose crystals, produced in solution, was by Ranby and Noe in 1961 [35]. This was followed by the first report of the production of cellulose nanowhiskers by acid hydrolysis [36]. Nanowhiskers of cellulose can also be extracted from the mantle of tunicates, a sea creature [37]. Tunicate nanowhiskers are reported to have moduli of $\sim 140 \mathrm{GPa}$ [17], but acid hydrolysed nanowhiskers are thought to have much lower moduli (50-100 GPa) [38]. The first report of the use of cellulose nanowhiskers in composite materials was by Favier et al. in 1995 [2]. They investigated the percolation of nanowhiskers extracted from tunicates. Since then a large number of groups have reported on the use of cellulose nanowhiskers and their use in composites, some of whom have contributed to this article; namely from Argentina at INTEMA, within the UK at the University of Manchester and the University of Nottingham, and from the USA at Case Western Reserve University, Virginia Tech and at Oregon State University.

The relative mechanical advantage of using cellulose nanofibres (nanowhiskers, nanofibrils) over conventional fibres is best shown graphically. Figure 2 shows HalpinTsai micromechanical predictions for unidirectional polypropylene matrix composites filled with $50 \mathrm{vol} \%$ of unidirectional cellulose fibres as a function of different fibre aspect ratios and Young's moduli. The Halpin-Tsai model $[39,40]$ is a short-fibre composite model which predicts all the elastic constants of composite materials as a function of the aspect ratio of the filler when the constituent properties and the volume fractions of the two phases (matrix and reinforcement) are known. 


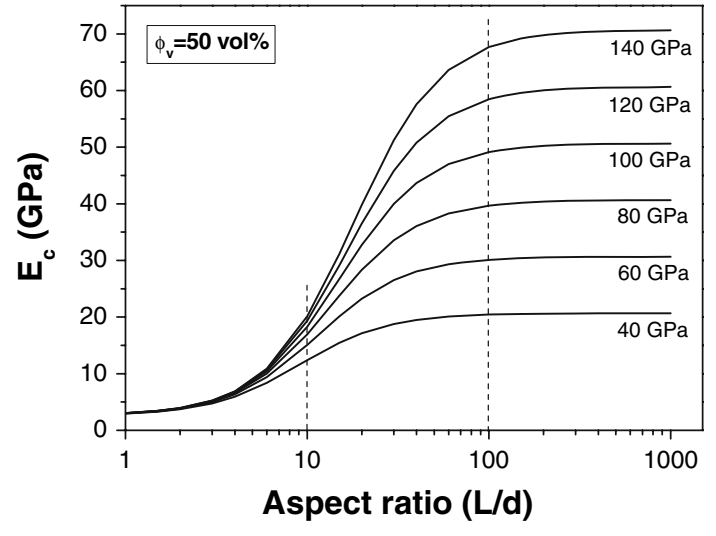

Fig. 2 Model plots of the Halpin-Tsai equation (Eq. 1) for a range of fibre moduli showing the predicted composite modulus $\left(E_{\mathrm{c}}\right)$ as a function of the aspect ratio of the fibre reinforcement. The model assumes a unidirectional composite sample, with no fibre-fibre interactions and a polypropylene matrix

The Halpin-Tsai equation can be written as

$\frac{E_{\mathrm{c}}}{E_{\mathrm{m}}}=\frac{1+\zeta \eta \varphi_{\mathrm{f}}}{1-\eta \varphi_{\mathrm{f}}}$

with

$\eta=\frac{\left(\frac{E_{\mathrm{f}}}{E_{\mathrm{m}}}-1\right)}{\left(\frac{E_{\mathrm{f}}}{E_{\mathrm{m}}}+\zeta\right)}$

where $E_{\mathrm{c}}, E_{\mathrm{f}}$ and $E_{\mathrm{m}}$ are respectively the composite, reinforcement and matrix Young's moduli; $\varphi_{\mathrm{f}}$ is the filler volume fraction and $\zeta$ a shape factor. The shape factors relative to fibres reinforcement has been chosen to be $(0.5 s)^{1.8}$, in accordance with a previous study [41], where $s$ is the aspect ratio. For a more extensive introduction to the model, the reader is referred to the relevant scientific literature $[39,40]$. The model supposes a perfect interface between matrix and fibre, but does not account for fibrefibre interactions, which can take place in high loading cellulose composite/nanocomposites (i.e. percolated networks). Young's modulus of cellulose fibres can vary according to the source, and fibre dimensions. A modulus of 40-60 GPa is usually found for natural bast fibres like flax and hemp (see Table 2), while it potentially increases up to $80 \mathrm{GPa}$ for single cells [42] and certainly in the range of 100-140 GPa for nanofibrils and nanowhiskers [17, 23]. Due to the intrinsic higher performances of nano-sized fillers, cellulose nanowhiskers are predicted to enhance stress transfer and therefore the final composite modulus (more than 3-fold) when compared with traditional micronsized cellulose fibres. It is clear from these data why the recent interest in studying nano-cellulose composite has occurred. Nevertheless, such effects can only be realised for fibres of a high-enough aspect ratio. Cellulose nanofibres with an aspect ratio smaller than 10 would not have any major benefits when compared with conventional micron-sized filaments. Only nanofibres with aspect ratios bigger than 50 can guarantee an efficient reinforcement effect. For aspect ratios larger than 100, Young's moduli reach a plateau, which correspond to the upper-limit case for reinforcement. For example, single flax fibres, which are around $25 \mathrm{~mm}$ long and $20 \mu \mathrm{m}$ thick, will have an aspect ratio of 1250 , which is well above the critical value. Since cellulose nanowhiskers generally have lower aspect ratios, typically between 10 and 30, there is a need for longer nanofibres of this type.

This article contains contributions to the field of cellulose nanocomposites in the areas of processing and characterisation and applications and new advances in the subject. It is intended that a flavour of current research taking place internationally will be given, rather than a general overview of the area of research. For other reviews of cellulose nanocomposites, the reader is referred to an article by Samir et al. [43] and another by Kamel [44]. Before each research contribution is reported, a detailed overview of nanowhisker and nanofibril properties will be given by Alain Dufresne at INP, Grenoble, France, who is a pioneer in this research area.

\section{An overview of cellulose whisker and nanofibre properties (Grenoble Institute of Technology (INPG), International School of Paper, Grenoble, France)}

As already mentioned, native cellulose present in macroscopic fibres, like for instance plant fibres, consists of a hierarchical structure. This hierarchical structure is built up by smaller and mechanically stronger entities consisting of native cellulose fibrils. These fibrils interact strongly and aggregate to form the natural or native cellulose fibres. The lateral dimension of these fibrils depends on the source of the cellulose but it is typically of the order of a few nanometres. The fibrils contain crystalline cellulosic domains but also noncrystalline domains located at the surface and along their main axis. The noncrystalline domains form weak spots along the fibril. These fibrils display high stiffness and are therefore suitable for the reinforcement of nanocomposite materials.

There are numerous methods to prepare nanofibres from natural cellulose fibres. The properties of these nanofibres will now be outlined in more detail. One method consists of submitting plant fibres to strong acid conditions combined with sonication. It leads to the hydrolysis of noncrystalline domains, and rod-like nanofibres called cellulose nanowhiskers result from this treatment. The dimensions of these resultant nanowhiskers depend on the source of the cellulose, but their length generally ranges between 100 and $300 \mathrm{~nm}$. Some typical transmission electron microscope 

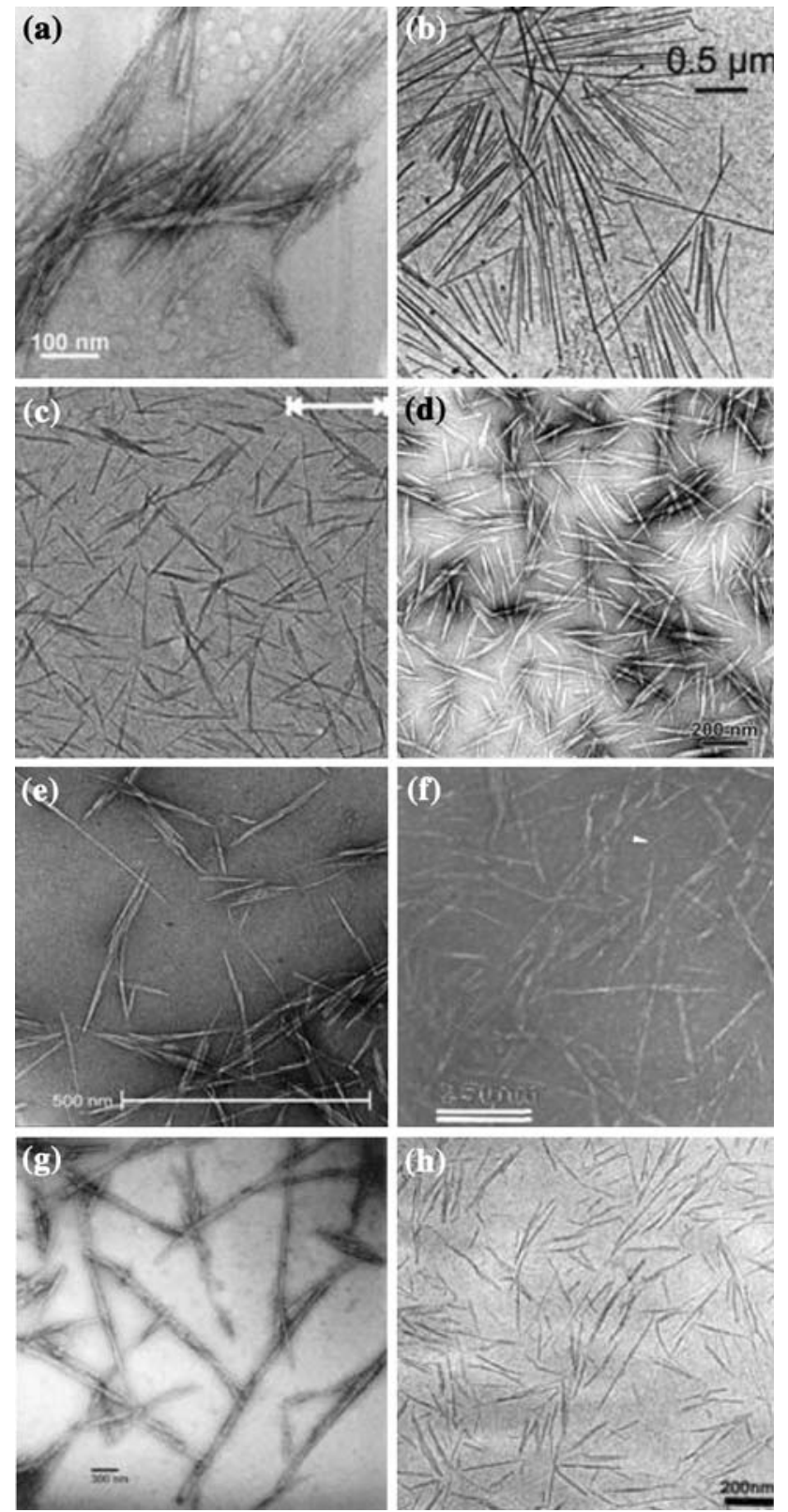

Fig. 3 Transmission electron microscope images of cellulose whiskers, obtained from acid hydrolysis of a microcrystalline cellulose [45], b tunicate [46], c cotton [47], d ramie [48], e sisal [49], f straw [50], $\mathbf{g}$ bacterial cellulose [51] and $\mathbf{h}$ sugar beet [52]. Reproduction of images a, b, c, e and $\mathbf{h}$ from [45], [46], [47], [49] and [52] with permission from American Chemical Society (C) American Chemical Society 2000, 2004, 2005, 2009); reproduction of image $\mathbf{d}$ from [48] with permission from Springer (ㄷ) Springer 2008); reproduction of image f from [50] with permission from Wiley (ㄷ Wiley 1996); reproduction of image $\mathbf{g}$ from [51] with permission from Springer (C) Springer 2002)

images of these nanowhiskers are reported in Fig. 3, taken from a number of publications [45-52].

By omitting the hydrolysis step and only submitting the fibres to high mechanical shearing forces, disintegration of the fibres occurs, leading to a material called microfibrillated cellulose (MFC). A combination of high mechanical shearing forces and mild enzymatic hydrolysis can also be used to prepare MFC [53]. These nanofibrils ideally consist of individual nanoparticles with a lateral dimension around $5 \mathrm{~nm}$. Generally, MFC consists of nanofibril aggregates, whose lateral dimensions range between 10 and $30 \mathrm{~nm}$, or more.

Among the many plant fibres used for the preparation of nanowhiskers, cotton constitutes the main source. The main reason is the high cellulose content of cotton that results in a higher yield when preparing cellulose nanowhiskers and avoids intensive purification of cellulose.

The main problem associated with making effective nanocomposites from cellulose nanofibres is related to their homogeneous dispersion within a polymeric matrix. Because of the high stability of aqueous suspensions of cellulose nanowhiskers, water is the preferred processing medium. Hydrosoluble polymers are therefore well adapted for the processing of cellulose nanowhisker reinforced nanocomposites [46, 54-64]. Solid nanocomposite films can be obtained by mixing, casting and evaporating the aqueous polymer solution and the aqueous suspension. A first alternative consists in using an aqueous dispersed polymer, e.g. latex [50, 65-75]. After mixing and casting the two aqueous suspensions, a solid nanocomposite film can be obtained by water evaporation and particle coalescence. A second alternative consists of using non-aqueous systems. This means that the nanofibres can be dispersed in a suitable organic medium with respect to the polymeric matrix. For instance, it is possible to coat the surface of nanofibres with a surfactant $[45,76]$. The chemical modification of a nanofibres' surface is another way to obtain dispersions in organic solvents. It generally involves reactive hydroxyl groups from the surface of polysaccharides [77-79]. Grafting of polymeric chains to the surface of polysaccharide nanofibres, using the grafting onto [80, 81] or grafting from [48, 82-84] techniques, have been reported. Recently, it was also shown that cellulose nanowhiskers can be dispersed in dimethylformamide, dimethyl sulfoxide or $N$-methyl pyrrolidine without additives or any surface modifications [85-87]. A solvent exchange procedure can also be used. Other possible processing techniques for the production of nanocomposites are filtration of suspensions of whiskers to obtain a film, and then immersion of this film in a polymer solution [26, 32, 88-94].

Although short fibres are being widely used for the processing of thermoplastic polymers and composites, very few studies have been reported concerning the processing of cellulose nanowhisker reinforced nanocomposites by melt extrusion methods [94]. An attempt to prepare nanocomposites based on cellulose nanowhiskers obtained from microcrystalline cellulose (MCC) and poly lactic acid (PLA) processed by a melt extrusion technique was 
recently reported [94]. The suspension of nanowhiskers was pumped into the polymer melt during the extrusion process. An attempt to use polyvinyl alcohol (PVA) as a compatibilizer to promote the dispersion of cellulose nanowhiskers within the PLA matrix has also been reported [95].

\section{Processing and characterisation of cellulose nanocomposites}

Elastomeric composites with cellulose whisker reinforcement (INTEMA, Universidad Nacional de Mar del Plata, Mar del Plata, Argentina)

Among the many applications of polyurethanes, the group at INTEMA, in collaboration with the group of Dr. Auad (Auburn University, USA), have explored the use of segmented polyurethanes as thermally triggered smart materials. In order to separate the nanowhiskers that form the microfibrils entangled in the structure, the acid hydrolysis method has been utilized. The exact details of the method were based on those reported by Dong et al. [96].

The negative surface charge induced during the preparation of cellulose nanowhiskers allows a quite stable dispersion in water [96-98]. This result initially led researchers in the area to prepare composites for which matrix and filler could be dissolved/suspended in water such as latex [2, 99, 100], starch [66, 98, 101] and poly(ethylene oxide) (PEO) [57, 59, 60]. Further interest to extend the use of the nanowhiskers to other matrices has resulted in a study of surface modifications [59] and the use of surfactants [76] as stabilizing agents.

Mirta Aranguren and co-workers at INTEMA have expanded these options by producing a stable cellulose nanowhisker suspension in dimethylformamide to be subsequently incorporated in different polyurethane (PU) matrices. This approach, which had been reported previously only by Dufresne's group [85], involves freeze drying of the initial aqueous suspension of the nanowhiskers, and then further redispersion in DMF. Berglund and co-workers [102] used a slightly different approach to produce highstrength cellulose-polyurethane elastomer nanocomposites.

One paramount condition for producing composites that take full advantages of the nano-size of the reinforcements is obtaining a good dispersion in the polymer. A cryogenic (liquid nitrogen) electron microscope image of cellulose nanowhiskers in polyurethane is shown in Fig. 4. It is clear from this image that a good dispersion of whiskers is achieved. The dispersion of the nanowhiskers in the unreacted liquid mixture of the polyol and isocyanate was studied through the rheological characterisation of these suspensions in the linear viscoelastic range (small

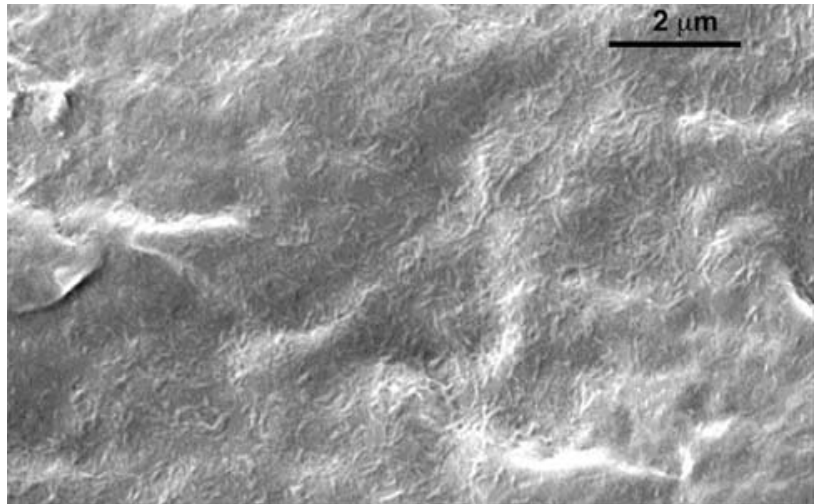

Fig. 4 A cryogenic electron microscope image of cellulose nanowhiskers dispersed in polyurethane [105]. Reproduction of image from [105] with permission from Wiley (c) Wiley 2008)

deformations). Room temperature measurements on the non-catalysed system confirmed that the system does not react in these conditions during the time of the test. This was also confirmed by the Newtonian behaviour (constant viscosity) of the solution without the presence of nanowhiskers [86]. The suspensions, on the contrary, become strongly shear-thinning by adding minimum amounts of cellulose crystals. Analysis of the storage modulus of the suspension (Fig. 5) shows that a discernable change occurred with an increasing nanowhisker concentration; from a Newtonian liquid (zero storage modulus for the solution without nanowhiskers) to a viscoelastic liquid and finally to a viscoelastic solid (cellulose nanowhisker concentrations up to $2.5 \mathrm{wt} \%)$. At a frequency of $1 \mathrm{rad} \mathrm{s}^{-1}$, a 2800 -fold increment in modulus of the suspension resulted from increasing the nanowhisker concentration from 0.25 to $5 \mathrm{wt} \%$,

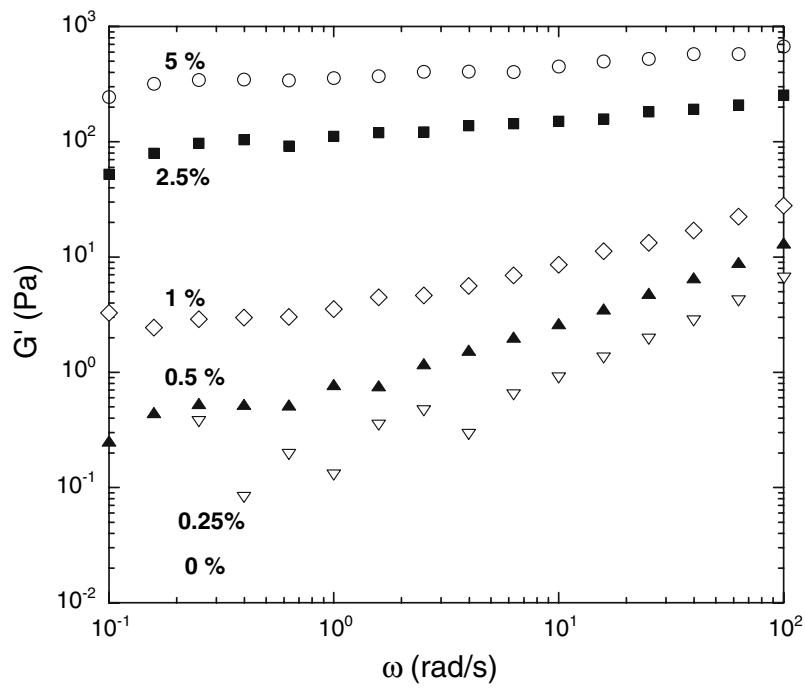

Fig. 5 Frequency sweep response of a mixture polyol-isocyanate and different percentages of cellulose nanowhiskers before reaction [86]. Reproduction of image from [86] with permission from Materials Research Society (ㄷ) Materials Research Society 2006) 
indicative of the formation of structure in the liquid, due to a pervading network of nanowhiskers. At $5 \mathrm{wt} \%$ (volume fraction $=0.033$ ), a concentration that would be considered fairly low for typical fillers, the low frequency viscosity is almost 6000 times that of the unfilled liquid mixture. A simple calculation showed that the uncured suspensions displayed a percolation behaviour with a threshold concentration of $0.88 \mathrm{wt} \%$ [86]. A polymerization reaction has also been carried out in the presence of the nanowhiskers, where their surface hydroxyl groups became covalently bonded to the matrix. The interfacial reaction was confirmed by FTIR spectroscopy [86].

Among the many applications of polyurethanes, the group at INTEMA have explored the use of segmented polyurethanes as thermally triggered smart materials. These materials have the ability of "remembering" their original shape after being deformed and of recovering from it, as a response to an external stimulus [103]. Because of this capability, they are also referred to as "shape memory" polymers. This particular behaviour is the result of the two-phase molecular structure of segmented polyurethanes. One phase, called the soft segment phase, consists of a long chain diol that gives extensibility to the PU and can crystallize by cooling. This phase is responsible for fixing a transient shape and recovering the original one. The other phase, called the hard segment phase, is formed by the isocyanate and a short diol. Extensive hydrogen bonding occurs in this phase, which can also be crystalline. Hard segments are responsible for fixing the original shape. Based on the good dispersion of the cellulose nanowhiskers in a polyurethane network (as discussed previously), the INTEMA group also investigated the effect of reinforcing a shape memory PU with these nanofibres. The efficiency of the dispersion allows the original transparency of the polymer in the composite films produced to be maintained.

Segmented polyurethanes (SPU) were synthesized to allow the introduction of the cellulose nanowhiskers before the PU reaction (SPU1), so that they became covalently attached to the polymer, and also after the reaction (SPU1*), where only physically strong interactions are possible. In both cases, the reinforcement was dispersed in DMF by ultrasonication before being used.

The sequence of incorporation of the cellulose nanowhiskers has notable consequences on the behaviour of the segmented PU [104]. For the SPU1 experiment, the addition of cellulose nanowhiskers gave typical results for the reinforcement of elastomers; an increase in modulus and a reduced elongation at break (Table 3). In SPU1*, only physical interactions between the nanowhiskers and the polymer were present, which can be broken and re-built during the tensile test. The elongation at break is remarkably less affected by the reinforcement than in the case of SPU1 (971 and 142\%, respectively).
Table 3 Tensile properties of the SPU and nanocomposite films: effect of cellulose incorporation sequence

\begin{tabular}{lll}
\hline & Modulus (MPa) & $\begin{array}{l}\text { Elongation } \\
\text { at break (\%) }\end{array}$ \\
\hline SPU, 0 wt\% cell & $4.54 \pm 0.32$ & 2165 \\
SPU1, 1.0 wt\% cell & $6.56 \pm 1.06$ & $142 \pm 28$ \\
SPU1 ${ }^{*}, 1.0$ wt\% cell & $5.91 \pm 0.50$ & $971 \pm 260$ \\
\hline
\end{tabular}

* Cellulose was incorporated after the PU had been reacted

More striking was the effect of the formation of covalent bonds between the cellulose and the PU on the shape memory behaviour of the resultant films. While the neat SPU and SPU1* showed shape memory behaviour, SPU1 did not have this capability. Cellulose covalently bonded to the matrix interferes, mainly, with the formation of the hard domains, which are responsible for fixing the original shape, thus erasing the functional property of the polymer.

From these results, it was clear that the cellulose nanowhiskers should be added to already synthesized PU if shape memory properties are to be maintained. Subsequent work was continued on composites prepared with a commercial SPU (IROGRAN PS455-203, Hunstman) and nanowhiskers. The shape memory behaviour of this system was studied through thermo-mechanical cyclic experiments. The samples were deformed at $T_{\mathrm{s}}$, a temperature above the soft segment melting temperature $\left(T_{\mathrm{m}, \mathrm{s}}\right)$ and below the hard segment melting temperature, so that the material exhibited rubber elasticity. After being deformed at $T_{\mathrm{s}}$ and subsequently cooled below $T_{\mathrm{m}, \mathrm{s}}$ under constraint, the deformed shape is fixed. When reheating at $T_{\mathrm{s}}$, the original shape is substantially recovered due to the elastic energy stored during the deformation process.

All the nanocomposite films displayed shape memory properties (Fig. 6), with percentages of recovery of the order of $95 \%$ (with reference to the second and subsequent cycles). Although the rigidity of the composites was markedly improved by the addition of nanowhiskers (addition of just $1 \mathrm{wt} \%$ of cellulose nanowhiskers increased the tensile modulus by $54 \%$ and reduced creep by $36 \%$ ), extensibility of the composites was not substantially reduced. On the other hand, the improved rigidity did not have a significant effect on the recovery of the material. The shape memory behaviour continued to be controlled by the polymer properties under the testing conditions [105].

Interfacial micromechanics of cellulose whisker nanocomposites (University of Manchester, Manchester, UK)

Work is underway at Manchester by Stephen Eichhorn and co-workers to investigate the reinforcing capabilities of cellulose nanowhiskers and nanofibrils in composite 

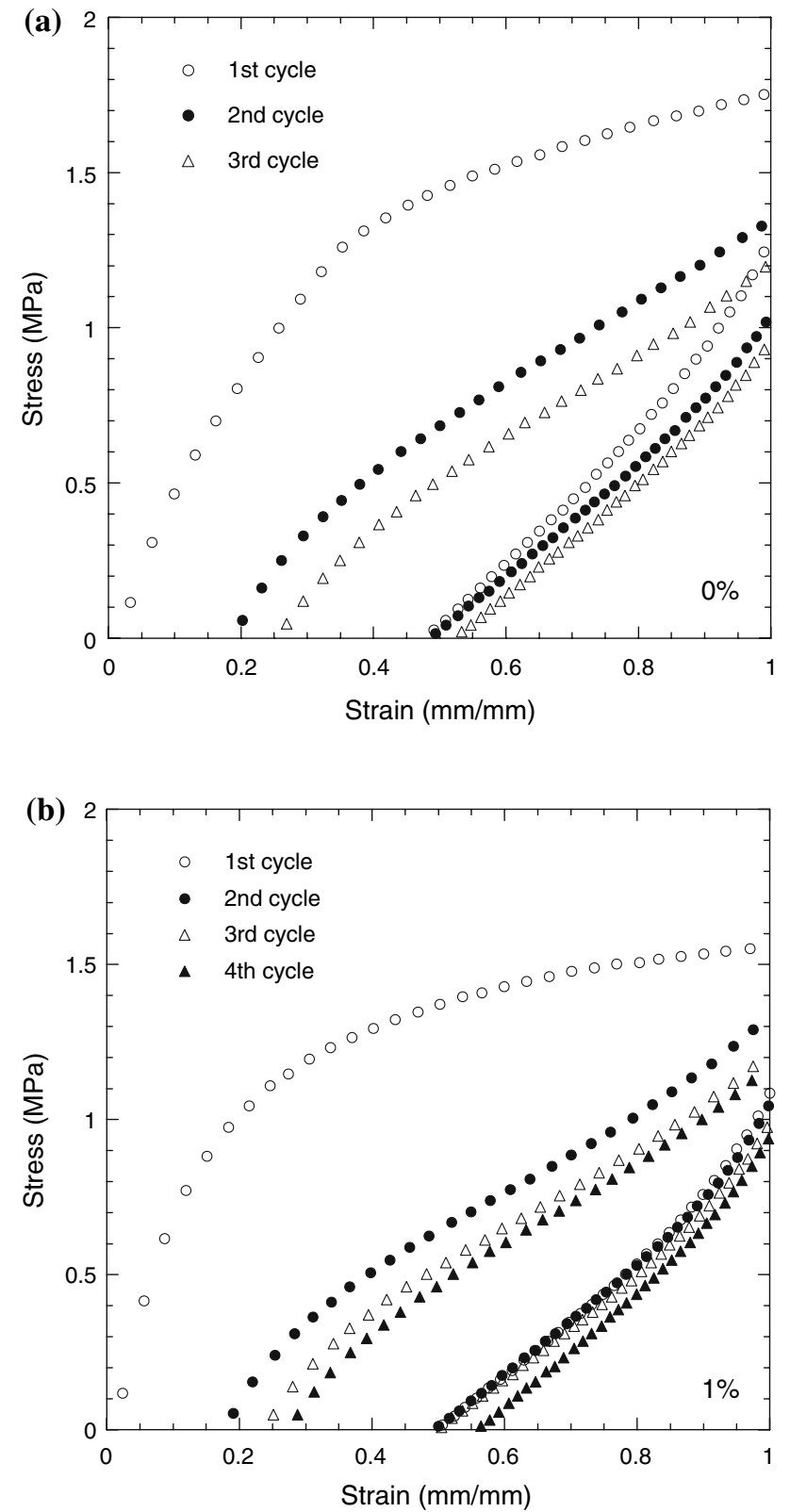

Fig. 6 Thermo cycling (shape memory behaviour) of a neat SPU (commercial) and b SPU containing $1 \mathrm{wt} \%$ nanocellulose [105]. Reproduction of image from [105] with permission from Wiley (C) Wiley 2008)

materials, by directly measuring stresses within the nanofibres using Raman spectroscopy. This experimental approach relies on the measurement of a shift in the position of characteristic peaks within the Raman spectrum of cellulose when these nanocomposite materials are deformed. The materials that have been investigated so far are cellulose nanowhiskers produced by extraction from tunicates, acid hydrolysis of cotton and also sheets of BC. In order to deform the nanowhiskers, the group has been dispersing and embedding them in an epoxy resin beam and applying deformation using a 4-point bending rig [17, 38]. The 4-point bending of these samples can be performed to place the whiskers in both tension and compression. Sheets of BC have been deformed in tension using a customised deformation rig that can be placed under the Raman spectrometer microscope.

The use of Raman spectroscopy to follow the deformation of polymer fibres and composites began in the 1970s with the discovery that peaks within the spectrum obtained from polydiacetylene single crystals changed position with the application of tensile deformation [106]. Following on from this, Galiotis et al. [107, 108] showed that it was possible to monitor this local deformation in both single Kevlar fibres, and when the same fibres were embedded in a composite material. This has led to a large number of papers on a variety of composites and fibre types, all of which have been recently reviewed [109]. In recent times this technique has been used to follow the deformation mechanisms in cellulose fibres and composites [110-118], and most recently cellulose nanocomposites $[17,23,38]$.

The Raman spectrum of cellulose is dominated by a highly intense carbonyl $(\mathrm{C}-\mathrm{O})$ stretch mode, located approximately at $1095 \mathrm{~cm}^{-1}$. It is the position of this band that has been mostly used to follow the local micromechanics of cellulose fibres, although other bands such as one located at $895 \mathrm{~cm}^{-1}$, assigned to heavy atom modes (COC, $\mathrm{COH}$ ) [119], have been used to follow the mechanics of cellulose fibre-polymer interfaces $[115,116]$. The Raman band located at $1095 \mathrm{~cm}^{-1}$ has been assigned to the carbonyl stretch $(\mathrm{C}-\mathrm{O})$ mode of the ring [119] and the glycosidic stretching mode $(-\mathrm{C}-\mathrm{O}-\mathrm{C}-)$ [117, 120]. Typical shifts in the Raman band located at $1095 \mathrm{~cm}^{-1}$, as a function of tensile deformation for cellulose nanowhiskers extracted from tunicates, are shown in Fig. 7a [17]. The shift plateaus at high strain due to the debonding of nanowhiskers from the matrix [17]. The shift in the peak position of the Raman band located at $1095 \mathrm{~cm}^{-1}$, before debonding occurs, was found to be highly sensitive to the application of tensile deformation, which indicates that the molecular chains of the cellulose structure are being deformed. The rate of shift of this band with respect to strain has been related to the modulus of the whiskers. By assuming that the whiskers have a uniform stress microstructure, it is possible to show, using an analysis by Krenchel [121] for a 2D random in-plane distribution of reinforcing elements, that they have a modulus of $143 \mathrm{GPa}$ [17]. A recent AFM bending experiment on single tunicate whiskers has confirmed this value [122]. Similar band shifts have been obtained for cellulose whiskers produced by acid hydrolysis of cotton, as shown in Fig. 7b [38]. Using the same analysis as used for the tunicate whiskers, moduli of $57 \mathrm{GPa}$ (2D networks) and $105 \mathrm{GPa}$ (3D 

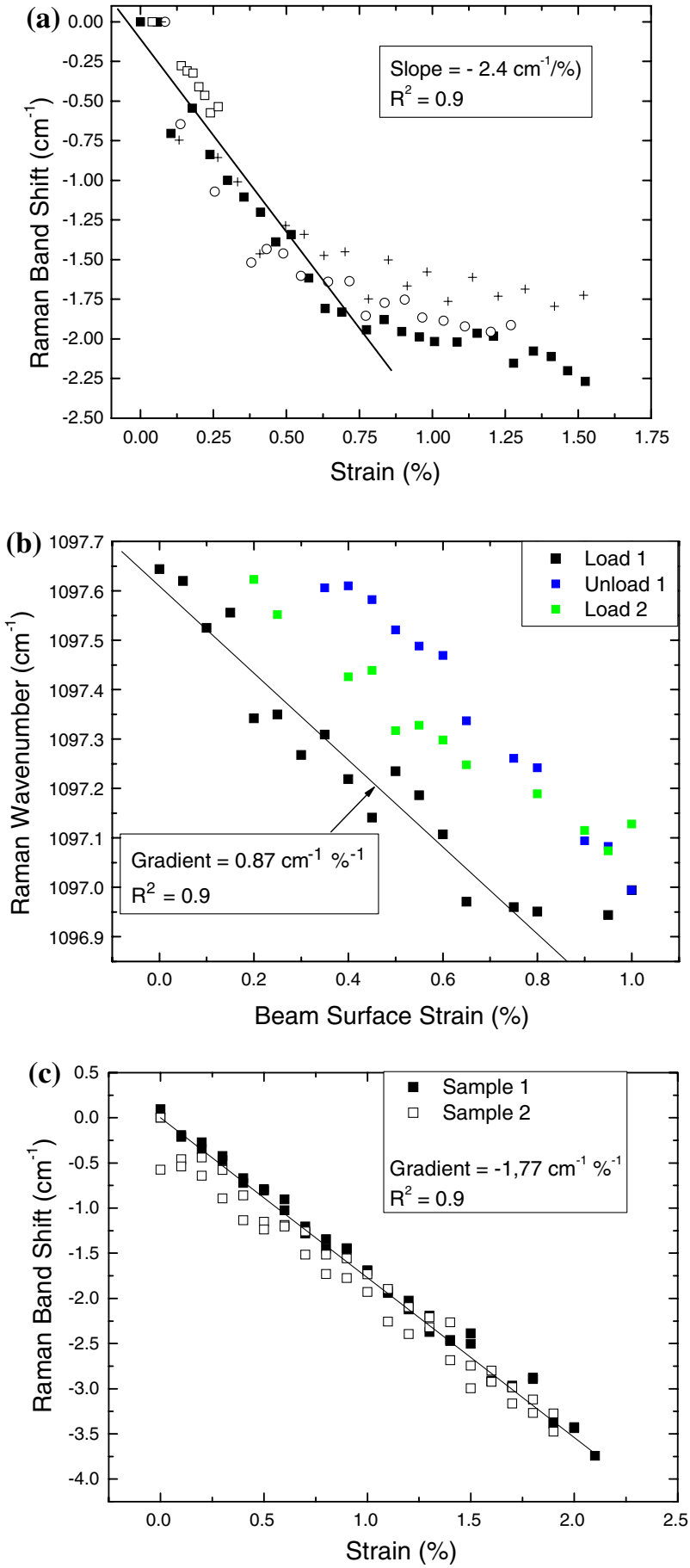

Fig. 7 Shifts in the band positions for the $1095 \mathrm{~cm}^{-1}$ Raman peak from a tunicate cellulose whiskers embedded in epoxy resin and deformed under 4-point bending in tension, b acid hydrolysed cellulose whiskers embedded in epoxy resin and deformed under 4-point bending in tension (samples were loaded and unloaded for 1 cycle) and $\mathbf{c}$ two fibrous networks of bacterial cellulose deformed independently in tension. Reproduction of image a from [17] with permission from American Chemical Society (C) American Chemical Society 2005), b from [38] with permission from the American Physical Society (ㄷ American Physical Society 2008) and c from [23] with permission from Springer (C Springer 2008) networks) were obtained. These values are significantly lower than for tunicate whiskers, which may be an indication of a lower crystallinity for these nanowhiskers, possibly induced by the chemical processing route. This low value for the modulus may also arise due to the smaller aspect ratio of cellulose nanowhiskers produced by acid hydrolysis compared to tunicate whiskers, and hence an inferior stress-transfer efficiency.

$\mathrm{BC}$ nanofibrils, as already discussed in the section "An overview of cellulose whisker and nanofibre properties (Grenoble Institute of Technology (INPG), International School of Paper, Grenoble, France)", have a completely different morphology to the nanowhisker form. The nanofibrils of this form of cellulose generally form a network structure, rather like that seen in paper. The modulus of BC nanofibrils has been previously measured using an AFM cantilever method, yielding a value of $78 \mathrm{GPa}$ [22]. Figure $7 \mathrm{c}$ shows a shift recorded in the position of the $1095 \mathrm{~cm}^{-1}$ band as a function of strain applied to a fibrous network of BC fibrils [23]. After confirming that the BC samples comprised a random 2D network of fibres, it was possible to show that the modulus of an individual fibril was $114 \mathrm{GPa}$ [23]. This value, although higher than the one obtained by the AFM method, is lower than the crystal modulus of cellulose ( $\sim 138 \mathrm{GPa})[10]$ and tunicate cellulose whiskers. The reason for this lower value was thought to be because BC has a lower crystallinity (about $80 \%$ ) than tunicate cellulose nanowhiskers [23].

Exploiting hydrogen bonding for the processing of cellulose nanocomposites (Case Western Reserve University, Cleveland, USA)

Jeff Capadona, Stuart Rowan and Christoph Weder at Case Western University, USA, have been investigating the ability to switch hydrogen bonding in cellulose nanocomposites, to render them flexible when immersed in water.

Owing to their strongly interacting surface hydroxyl groups, cellulose nanowhiskers have a significant tendency for self-association [123]. This is, in principle, a very desirable feature for the formation of load-bearing percolating architectures within a host polymer matrix: the spectacular reinforcement observed for polymer/cellulose nanowhisker nanocomposites can be attributed to the formation of rigid nanowhisker networks in which stress transfer is facilitated by hydrogen-bonding among the nanowhiskers [17]. However, these same nanowhiskernanowhisker interactions can also cause nanowhisker aggregation during the nanocomposite fabrication; this, of course, limits the extent of mechanical reinforcement $[124,125]$. Good dispersion during processing is achieved when nanowhisker self-interactions are "switched off" by 
competitive binding with a hydrogen-bond-forming solvent. Since water disperses most types of cellulose nanowhiskers well, the mixing of aqueous polymer solutions or emulsions with cellulose nanowhisker suspensions and subsequent film casting has for a long time been the primary method to process polymer/nanowhisker nanocomposites [43]. Furthermore, several "solubilizing schemes" have been explored to improve nanowhisker dispersibility in organic media, including the use of surfactants [125, 126], silylation [77], grafting of PEO [127] or maleated polypropylene [125] and acylation [128]. However, these surface modifications usually also reduce the interactions among the nanowhiskers and thereby the macroscopic mechanical properties of the corresponding nanocomposites. Turbak and co-workers have shown that stable suspensions of tunicate nanowhiskers with negatively charged sulfate groups, commonly produced by hydrolysis of the native cellulose with sulfuric acid [43, 123, 129], can also be produced in dimethylsulfoxide (DMSO) [130], $N, N$-dimethyl formamide (DMF) [85, 86], $N$-methyl pyrrolidine (NMP) [87], formic acid [87] and $m$-cresol [87] for example by lyophilization of aqueous whisker dispersions and re-dispersion of the resulting aerogel in the organic solvent [87]. Gray has produced similar cellulose nanowhisker dispersions in polar organic solvents using whiskers obtained from cotton [131]. Cellulose nanowhiskers without surface charges [132, 133], prepared by hydrolysis with $\mathrm{HCl}$, do not disperse as well in aprotic solvents (DMSO, DMF, NMP); however, formic acid and $m$-cresol have been shown to also disperse non-charged nanowhiskers properly [87].

The ability to break hydrogen bonds and disperse cellulose nanowhiskers in hydrogen-bond-forming organic solvents opens the door for the fabrication of nanocomposites with a broad range of polymer matrices. For example, Weder and co-workers [134] reported nanocomposites derived from tunicate nanowhiskers and (semi)conducting $\pi$-conjugated polymers, including doped polyaniline (PANI) and a poly( $p$-phenylene ethenylene) (PPE) derivative with quaternary ammonium side chains. These materials were solution-cast from formic acid. Measurements of electrical conductivity, photoluminescence, and mechanical properties reveal that the nanocomposites synergistically combine the electronic characteristics of the conjugated polymers with the outstanding mechanical characteristics of the cellulose scaffold. Rowan and Weder reported percolating nanocomposites with polystyrene or an ethyleneoxide/epichlorohydrin copolymer (EO-EPI) matrix and systematically investigated such materials prepared with either tunicate or cotton nanowhiskers [135]. In the rubbery regime of these materials, which were prepared by solution-casting from DMF, the shear moduli $\left(G^{\prime}\right)$ increased by over two orders of magnitude at a nanowhisker content of $\sim 20 \% \mathrm{v} / \mathrm{v}$ (Fig. 8). This spectacular reinforcement is related to the

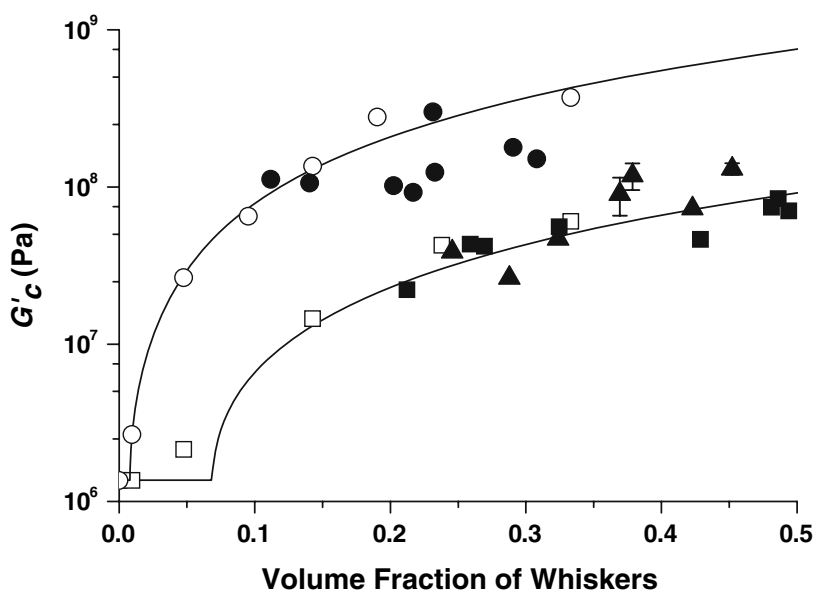

Fig. 8 Shear moduli $G^{\prime}$ of cellulose whisker nanocomposites with EO-EPI as a function of composition. The nanocomposites were fabricated by either solution casting (open symbols) or the template approach (filled symbols) and shear moduli $G^{\prime}$ were determined by DMTA at $25{ }^{\circ} \mathrm{C}$. Data are for nanocomposites comprising cellulose whiskers isolated from tunicate whiskers (circles), cotton (squares) and microcrystalline cellulose (triangles), respectively. Solid lines represent predictions by the percolation model (Eq. 3). Reproduction of image with permission from AAAS (C AAAS 2008)

formation of a percolating nanofibre network in which stress transfer is facilitated by hydrogen-bonding between the nanowhiskers. The mechanical properties can be predicted by a percolation model, which expresses $G_{\mathrm{c}}^{\prime}$ as $[136,137]$

$G_{\mathrm{c}}^{\prime}=\frac{\left(1-2 \psi+\psi X_{\mathrm{r}}\right) G_{\mathrm{s}}^{\prime} G_{\mathrm{r}}^{\prime}+\left(1-X_{\mathrm{r}}\right) \psi G_{\mathrm{r}}^{\prime 2}}{\left(1-X_{\mathrm{r}}\right) G_{\mathrm{r}}^{\prime}+\left(X_{\mathrm{r}}-\psi\right) G_{\mathrm{s}}^{\prime}}$

with

$\psi=X_{\mathrm{r}}\left(\frac{X_{\mathrm{r}}-X_{\mathrm{c}}}{1-X_{\mathrm{c}}}\right)^{0.4}$

where $X_{\mathrm{r}}$ is the volume fraction of the rigid (r, nanowhisker) component, $G_{\mathrm{s}}^{\prime}$ and $G_{\mathrm{r}}^{\prime}$ are the shear moduli of the neat soft (s, polymer) and rigid constituents, and $\psi$ is the volume fraction of nanowhiskers. Figure 8 shows that Eq. 3 matches excellently with the experimentally determined $G_{\mathrm{c}}^{\prime}$ values of EO-EPI nanocomposites comprising nanowhiskers isolated from tunicates and cotton [135].

To produce cellulose nanocomposites with hydrophobic polymers, Weder and Rowan introduced a template approach to nanocomposite fabrication [135]. The process is based on the formation of a three-dimensional template scaffold of well-individualized nanowhiskers, which is subsequently filled with a polymer of choice (Fig. 9a). The first step is the formation of a nanofibre template through a sol/gel process. For cellulose nanowhiskers this involves the formation of an aqueous nanowhisker dispersion, which is converted into a gel through solvent-exchange with a 
(a)

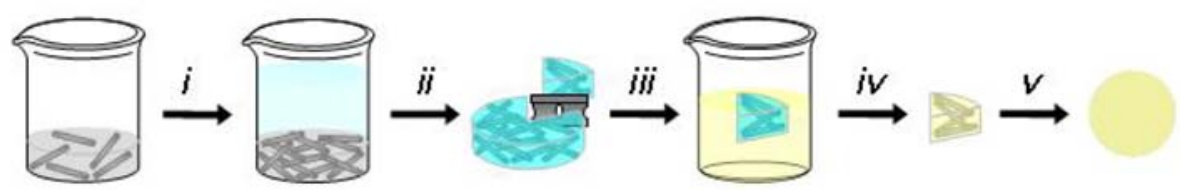

(b)

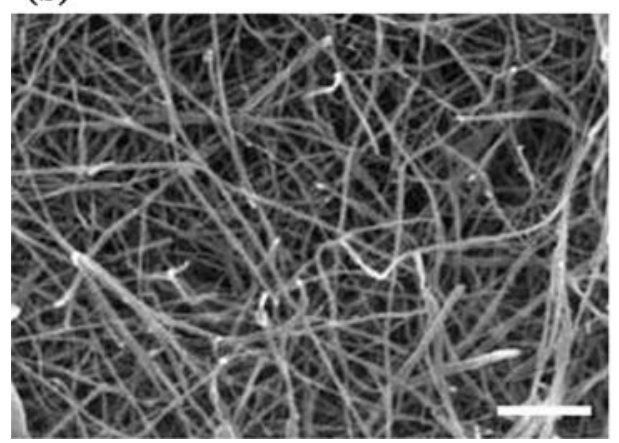

Fig. 9 a Schematic of the template approach to well-dispersed polymer/cellulose whisker nanocomposites. $i$ A non-solvent is added to an aqueous whisker dispersion in the absence of any polymer. ii Solvent exchange promotes the self-assembly of a nanofibre gel. iii The gelled nanofibre scaffold is imbibed with a polymer by immersion in a polymer solution, before the nanocomposite is dried

water-miscible solvent, for example acetone, that "turns" the hydrogen bonding between the nanowhiskers back on. That is to say replacing the water with a weaker hydrogen bonding solvent (e.g. acetone) results in the reestablishment of hydrogen bonding between the whiskers. This nanofibre template, which displays a percolating network structure (Fig. 8b), is then filled with a matrix polymer by immersing the gel into a polymer solution, in a solvent that does not disperse the nanowhiskers, and subsequent drying and shaping. Weder and Rowan demonstrated that this technique, which is somewhat different from other recently developed "impregnation schemes" [32, 93], is applicable to cellulose nanowhiskers isolated from tunicates, cotton, MCC and other nanofibres, such as carbon nanotubes [135, 138]. To evaluate the template approach, cellulose nanowhisker nanocomposites with EO-EPI were studied in detail (Fig. 8). Gratifyingly, the materials prepared by the template approach show identical mechanical properties to materials prepared by solution casting from DMF, indicative of the formation of percolating networks. It was previously difficult to incorporate cellulose nanowhiskers into non-polar polymers such as polypropylene or polybutadiene without surface modification or surfactants. Thus, probably the most important feature of the template approach is its capability to access percolating nanocomposites of otherwise immiscible components. This was demonstrated for polybutadiene/tunicate nanowhisker nanocomposites, which exhibit the mechanical properties predicted by the percolation model [135]. (iv) and compacted (v). b Scanning electron microscopy image of a cellulose whisker aerogel, prepared by supercritical extraction of a whisker acetone gel (Fig. 2a, ii) (scale bar $=200 \mathrm{~nm}$ ). Reproduction of images a and $\mathbf{b}$ from [135] with permission from Nature Publishing Group (c) Nature Publishing Group 2007)

Recognizing that switching the interactions among nanowhiskers in a solid nanocomposite through an external stimulus could be a way to create a new type of mechanically adaptive material, Weder and Rowan took the concept of controlling nanowhisker-nanowhisker interactions one step further and introduced a new family of morphing materials, in which a chemical stimulus causes a significant and reversible stiffness change [139, 140]. The material's design mimics the structural concepts at play in the dermis of sea cucumbers (Fig. 10) [140]. These creatures have the fascinating ability to rapidly and reversibly alter the stiffness of their skin when threatened. This dynamic mechanical behaviour is achieved through a nanocomposite architecture, in which rigid, high-aspect-ratio collagen fibrils reinforce a viscoelastic matrix (Fig. 10). The stiffness of the tissue is regulated by controlling the fibrillar interactions (through either non-covalent [141, 142] or covalent [143] bonds) and therewith the stress transfer, among adjacent collagen fibrils by locally secreted proteins. Rowan and Weder prepared and studied chemoresponsive materials, which mimic this architecture and whose morphing mechanical characteristics are very similar to those of the biological model [144, 145]. For example, they demonstrated that nanocomposites based on a rubbery poly(ethylene oxide) copolymer and a percolating network of tunicate nanowhiskers can exhibit a reversible, 40-fold modulus reduction upon exposure to a chemical regulator that switches off the hydrogen bonds among the nanofibres. This can be done through the 
(a)

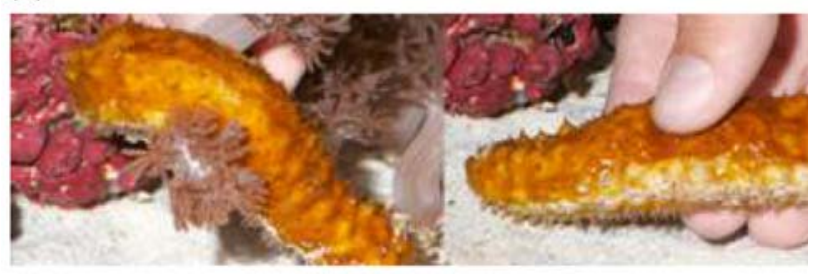

(b)

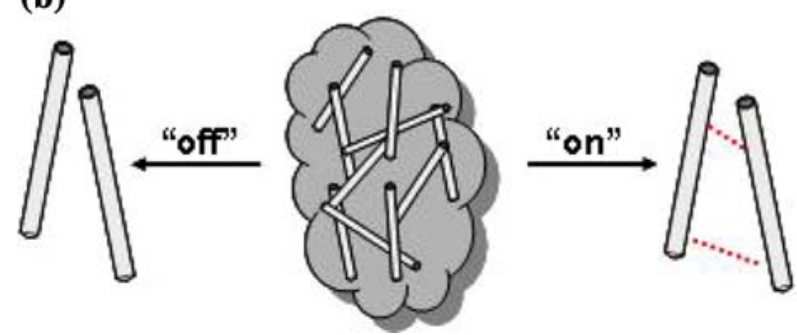

Fig. 10 a Pictures of a sea cucumber in soft and stiff state and b schematic of the switching mechanism in this biological model and the proposed biomimetic nanocomposites. The stress transfer among rigid, percolating nanofibres, and therewith the overall stiffness of the material, is controlled by a stimulus. Reproduction of images $\mathbf{a}$ and $\mathbf{b}$ from [139] with permission from AAAS (ㄷ AAAS 2008)

addition or removal of water, which acts as a chemical regulator that changes the hydrogen bonding between the whiskers within the polymer matrix, and at the same time presumably also impacts the whisker/matrix interactions. True to the intended design, the uptake of a small amount of water causes a dramatic modulus reduction (e.g. from 800 to $20 \mathrm{MPa}$ for a composite comprising $19 \mathrm{vol} \%$ nanowhiskers); the original stiffness is restored when the composites are dried. Control experiments and analyses using mechanical models support the conclusion that the stiffness change is due to the designed mechanism of altered nanowhisker-nanowhisker interactions, rather than alternative effects such as plasticization of the matrix.

Polymerisation from the surface of cellulose whiskers (University of Nottingham, UK)

Polymers can be grown from cellulose nanowhiskers directly using the surface hydroxyl groups as initiating sites, or the surface can be modified to introduce different initiator sites needed for controlled polymerisation techniques such as atom transfer radical polymerisation (ATRP) or reverse addition fragmentation radical polymerisation (RAFT). Wim Thielemans at the University of Nottingham is currently working on the surface modification of cellulose nanowhiskers and has recently reported on this approach, as have some other authors.

Surface initiated polymerisation techniques have been used extensively to graft polymers from the surface of macroscopic cellulose fibres [146-154]. Extending these techniques to cellulose nanowhiskers is a logical step. Indeed, surface initiated polymerisation from the surface of cellulose nanowhiskers is currently receiving a large amount of attention and numerous presentations at conferences have been given [155-159]. However, to date, only four publications have appeared in the literature: Habibi et al. [48] reported the ring opening polymerisation of $\varepsilon$-caprolactone using the surface hydroxyl groups as initiator sites, while both $\mathrm{Yi}$ et al. [82] and Morandi et al. [83] reported the grafting of polystyrene using surface initiated ATRP after grafting of an isobutyryl bromide moiety to the surface of the nanowhiskers to introduce the necessary initiator sites. Xu et al. [160] reported on the grafting of 6-[4-(4-methoxyphenylazo) phenoxy] hexylmethacrylate (MMAZO) from the surface of cellulose nanocrystals using ATRP after similarly grafting an isobutyryl bromide moiety to the surface of the nanowhiskers to introduce the necessary initiator sites. Simplified reaction schemes are given in Fig. 11.

Grafting of poly( $\varepsilon$-caprolactone) (PCL) from the surface of ramie cellulose nanowhiskers was performed in toluene using stannous octoate $(\mathrm{Sn}(\mathrm{Oct}) 2)$ as the catalyst [48]. The authors reported a final PCL content of $85 \mathrm{wt} \%$ in the modified nanowhiskers. However, as the modified nanowhiskers were not extracted but purified by a solubilisationcentrifugation sequence, "contamination" of the modified nanowhiskers by physically absorbed polymer chains could not be excluded. The PCL-grafted cellulose nanowhiskers were subsequently shown to increase the mechanical properties of PCL-cellulose nanowhisker composites more than unmodified cellulose nanowhiskers, indicating great potential in nanocomposite reinforcement applications.

Surface initiated ATRP from the surface of cellulose nanowhiskers requires a two-step reaction: grafting of the initiator bearing a $\mathrm{C}-\mathrm{Br}$ or $\mathrm{C}-\mathrm{Cl}$ bond followed by polymerisation initiated by the addition of vinyl monomers and the catalyst $\mathrm{Cu}(\mathrm{I}) \mathrm{Br}($ or $\mathrm{Cu}(\mathrm{I}) \mathrm{Cl}$ if using a $\mathrm{C}-\mathrm{Cl}$ terminated initiator). An equilibrium between $\mathrm{Cu}(\mathrm{I}) \mathrm{Br}$ and $\mathrm{Cu}(\mathrm{II}) \mathrm{Br}_{2}$ (or between $\mathrm{Cu}(\mathrm{I}) \mathrm{Cl}$ and $\mathrm{Cu}(\mathrm{II}) \mathrm{Cl}_{2}$ ), the latter formed by extraction of bromide (or chloride) from the initiator giving rise to a radical, results in controlled polymer chain growth. For surface-initiated polymerisation, a dissolved sacrificial initiator is sometimes used, in addition to the surface initiator groups. The use of a sacrificial initiator allows the graft length to be tailored by changing the initial ratio [monomer]/[sacrificial initiator] and the final conversion (given that the amount of initiating sites on the nanowhiskers is negligible compared to the amount of sacrificial initiator) [149]. In addition, the non-grafted polymer chains formed through polymerisation from the sacrificial initiator allows for direct determination of the grown polymer using standard polymer characterisation techniques to verify whether controlled 
(a)
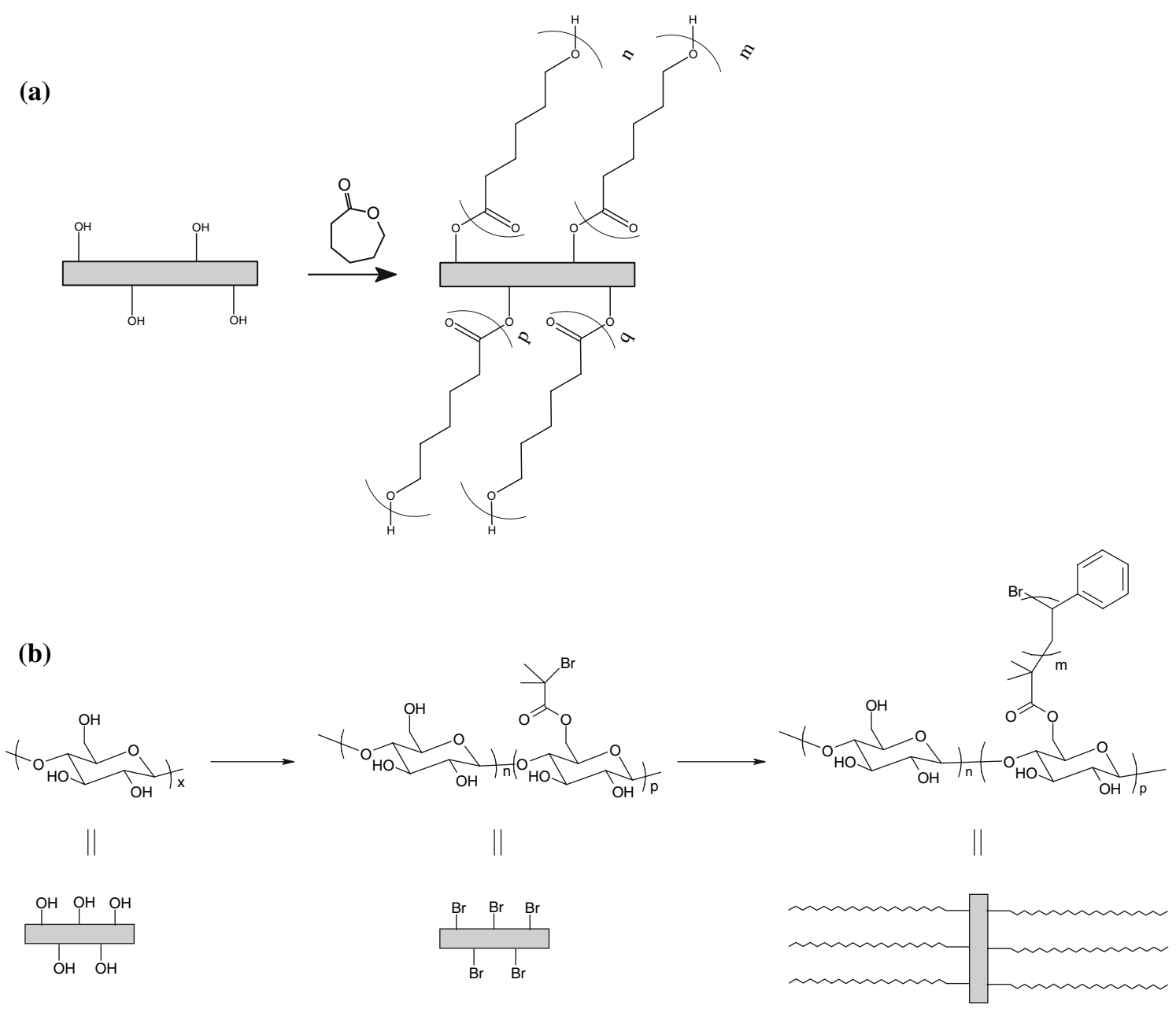

Fig. 11 Reaction scheme for the surface initiated polymerisation from the surface of cellulose nanowhiskers a by ring-opening polymerisation of $\varepsilon$-caprolactone, initiated from the surface hydroxyl groups and b by ATRP through grafting of 2-bromoisobutyryl

polymerisation conditions were obtained. Yi et al. [82] first grafted 2-bromoisobutyryl bromide to cotton nanowhiskers, followed by styrene polymerisation without the use of a sacrificial initiator. The final polystyrene content on the nanowhiskers, purified through soxhlet extraction, was determined to be $64 \mathrm{wt} \%$. The grafted polymer, removed from the surface through acid hydrolysis of the ester linkage of the initiator, was found to exhibit a relatively low polydispersity (PDI $=1.21$ ), showing good control of the polymerisation reaction. Through an investigation of the liquid crystalline phases of solutions of polystyrene-cellulose nanowhiskers, it was proved that the chiral nematic ordering of the cellulose nanowhiskers in solution is due to their shape, and not to the chiral nature of their surface. The same group also reported on successful grafting of poly(MMAZO) using ATRP without sacrificial initiator to the surface of the nanowhiskers derived from the acid hydrolysis of filter paper after bromide to introduce initiator sites followed by the controlled polymerisation of styrene. The grafted PCL chains are shown to have different length due to the uncontrolled nature of ring-opening polymerisation

derivatisation using 2-bromoisobutyryl bromide [160]. Grafting was confirmed by FTIR spectroscopy, TGA and DSC, and the grafting percentage was determined to be around $75 \%$ based on DSC data. However, no indication of the grafted chain lengths or control over the polymerisation was reported. The grafted nanowhiskers were subsequently tested for their liquid crystalline behaviour as a solution in chlorobenzene. A lyotropic nematic phase was seen to appear, with turbidity observed at room temperature for concentrations above $5.1 \mathrm{wt} \%$. Morandi et al. [82] first studied various reaction conditions for the grafting of the initiator, 2-bromoisobutyryl bromide, to the surface of nanowhiskers, followed by a series of polymerisations resulting in polystyrene brushes with different graft lengths. By controlling the grafting density of the initiator they were able to control the grafting density of the final polymer chains, while control over the polymerisation allowed them to control the length of the 
polymer chains. A maximum surface modification with initiator up to $70 \%$ was achieved, as well as a polystyrene content up to $22 \mathrm{wt} \%$. The control over the polymer chain length and grafting density is important when the surface properties need to be specifically tailored. They subsequently used polystyrene-grafted nanowhiskers to absorb 1,2,4-trichlorobenzene, a persistent organic pollutant, from water, opening up an interesting new application of surface modified cellulose nanowhiskers.

Analysis of dispersion of cellulose nanofibres and TEMPO oxidation to induce this dispersion (Virginia Tech, USA)

One of the main challenges in the use of cellulose nanowhiskers for polymer reinforcement is achieving a uniform distribution in a matrix material. Analysis of the nanowhisker distribution in cellulose nanocomposites by transmission electron microscopy is hampered by the limited contrast between the organic nanowhiskers and the organic matrix. Maren Roman at the Department of Wood Science and Forest Products, Virginia Tech, has developed a method for fluorescent labelling of cellulose nanowhiskers [161], potentially enabling the use of fluorescence or laser scanning microscopy to analyze particle distribution in cellulose nanocomposites, as has recently been applied to clay nanocomposites [162, 163].

Labelling was achieved via a three-step reaction (Fig. 12) involving activation of the surface hydroxyl groups with epichlorohydrin followed by opening of the oxirane ring with ammonium hydroxide. The thus aminated crystal surface was then reacted with fluorescein-5'-isothiocyanate (FITC) resulting in a label density of one FITC moiety per $27 \mathrm{~nm}^{2}$. The FITC-labelled cellulose nanowhiskers showed $\mathrm{pH}$-sensitive absorbance in the blue and blue-green transition regions of light, resulting in a yellow appearance (Fig. 12). The fluorescence emission maximum of FITC occurs at $518 \mathrm{~nm}$.
When analyzing particle dispersions in nanocomposites by fluorescence microscopy [162, 163], the degree of particle agglomeration is deduced from the homogeneity of fluorescence intensity across the specimen. Agglomerates are discernible by their higher local fluorescence intensity. Laser scanning microscopy with its ability to produce a series of thin $(0.1-1.5 \mu \mathrm{m})$ optical sections of the fluorescent specimen, which can then be stacked to produce a $3 \mathrm{D}$ representation, offers the possibility to analyse the dispersion of fluorescent particles in nanocomposites in the $x-, y$-, and $z$-direction. Thus, fluorescent labelling of cellulose nanowhiskers in combination with fluorescence or laser scanning microscopy may become a valuable tool in the optimization of processing conditions for minimal agglomeration in cellulose nanocomposites.

Adequate dispersion and distribution of fibre reinforcement leads to optimum performance of the composite. The mechanical properties are also dictated by the length of the particle and more importantly the aspect ratio of the nanofibre. To this end, great effort has gone into describing the length and diameter of acid hydrolyzed cellulose nanowhiskers. Atomic force microscopy [164] and transmission electron microscopy [165] studies have quantitatively revealed average length and diameter of cellulose nanowhiskers. From these studies, nanowhiskers from wood have average lengths reported in the range between 105 and $150 \mathrm{~nm}$ and diameters 4.9-12 nm. Aspect ratios of the nanowhiskers are between 10 and 30. Other nanoscale celluloses like MFC maintain the length of the nanofibril providing higher aspect ratios. MFC is derived from unraveling the microfibril structure of the cell wall using severe mechanical treatment $[166,167]$. This material has a unique mesh containing tens of nanometre diameter fibrils appearing to have micrometer lengths.

Since the original studies in the 1980s, MFC was produced with pretreatment stages that lower the energy requirement by loosening the hydrogen bonds amongst nanofibrils with enzyme and chemical treatments
Fig. 12 Reaction scheme for the labelling of cellulose nanowhiskers with fluorescein$5^{\prime}$-isothiocyanate and image showing aqueous suspensions of (A) cellulose nanowhiskers $(0.8$ wt $\%)$ and $(B)$ FITC-labelled cellulose nanowhiskers $(0.5$ wt\%). Reproduction of images $\mathbf{a}$ and $\mathbf{b}$ from [161] with permission from American Chemical Society (C) American Chemical Society 2007)

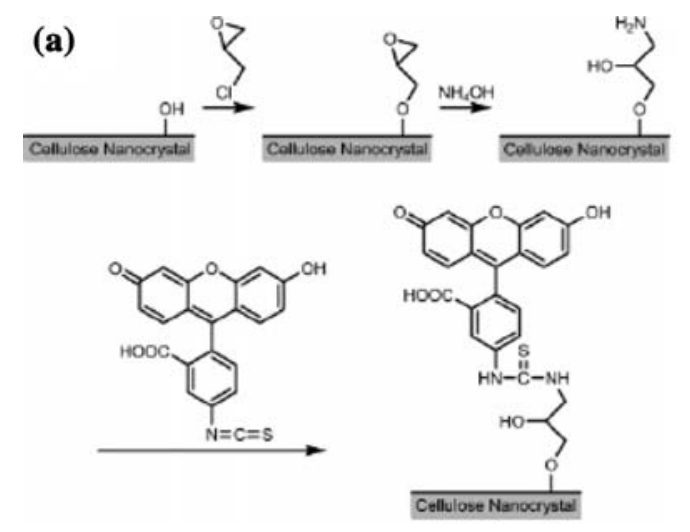

(b)

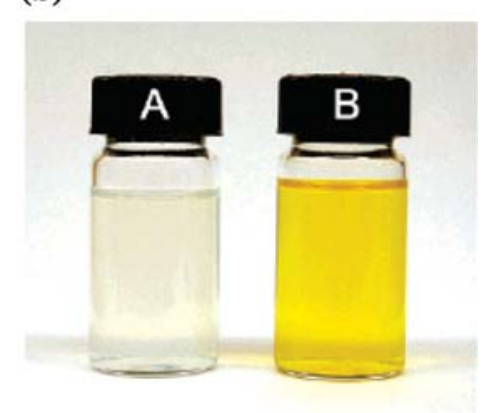


[168, 169]. Recently, renewed interest in this material, which has dimensions of carbon nanotubes, has led to the development of low energy methods for isolation by such equipment as a blender or even a magnetic stir plate [170, 171]. Isogai and co-workers [172] showed that after cellulose pulps are oxidized in a heterogeneous suspension with 2,2,6,6 tetramethyl-1-piperidinyloxy (TEMPO) as a catalyst, the accessible primary hydroxyls on the surface of the microfibrils become modified with anionic carboxylate groups. As a result, the nanofibrils within the fibres can become unwound by mechanical agitation with repulsive forces between ionized carboxylates overwhelming the myriad of hydrogen bonds holding the nanofibrils together. Solutions of nanofibrils (3-5 nm diameter) are directly produced from the TEMPO-mediated oxidized pulp using mechanical agitation from a blender [173].

Scott Renneckar of Virginia Tech has a research program focussed on the nanoscience of cellulose and woodbased materials. Working with Johnson et al. [174], they have shown that TEMPO-oxidized pulp can be isolated by sonication without blending. A novel method to compare the effect of surface area on the mechanical reinforcement potential in thermoplastic composites was reported within that study; the sonication time of the TEMPO-oxidized pulp was varied influencing the yield of the nanofibrils. At 20 min of sonication, $98 \%$ of the pulp was converted into nanofibrils that had a width between 3 and $5 \mathrm{~nm}$, according to TEM measurements (Fig. 13) [174]. These nanofibrils showed better reinforcement of hydroxypropylcellulose, relative to acid hydrolyzed nanowhiskers, and 20-pass MFC (isolated without pretreatment).

With AFM, Li and Renneckar [175] investigated the length and thickness of TEMPO modified wood pulp fibre that underwent extensive sonication and found nanofibrils with unique dimensions. After $30 \mathrm{~min}$ of sonication, the nanofibrils had an average thickness value of $1.38 \mathrm{~nm}$ and length of $580 \mathrm{~nm}$. If the sonication time was increased to 4 $\mathrm{h}$, the average thickness of the nanofibrils decreased to $0.74 \mathrm{~nm}$ and length to $260 \mathrm{~nm}$. Interestingly, there was no correlation between length and thickness on individual nanofibrils and the average aspect ratio of these materials maintained a value around 500 [175]. This aspect ratio is remarkable for wood-based cellulose nanofibres and provides insight into the better composite performance highlighted by Johnson et al. [34].

\section{Applications and new advances in cellulose nanocomposites}

Reinforcing adhesives using cellulose nanofibres (BOKU, Vienna, Austria)

Adhesive bonding is a routine processing step in the wood industry. Potential routes for performance improvements of wood adhesives focus very much on polymer chemistry [176] but currently little attention is paid to the role of fillers. The example of reinforced epoxy, an adhesive typically not used in the wood industry, shows that the addition of fibrous filler primarily improves the toughness of an adhesive bond [177-184]. Confirming results achieved in modelling studies [185, 186], a comparative study of a broad variety of wood adhesives [187-189] indicated a strong correlation between the toughness of an adhesive and the ultimate shear strength of corresponding wood adhesive bonds. Urea-formaldehyde resins (UF) are a widely used class of low-priced wood adhesives, which are well known for their pronounced brittleness and their tendency to develop microcracks (Fig. 14) which limits their mechanical performance. The combination of low price and poor mechanical performance makes UF an ideal candidate for studying the effect of added filler.
Fig. 13 Nanocellulose prepared by TEMPO-mediated oxidation of pulp; a atomic force microscopy height image of nanocellulose deposited on mica, b $4 \%$ concentration of nanocellulose foam after blending oxidized pulp for $18 \min$ (a)

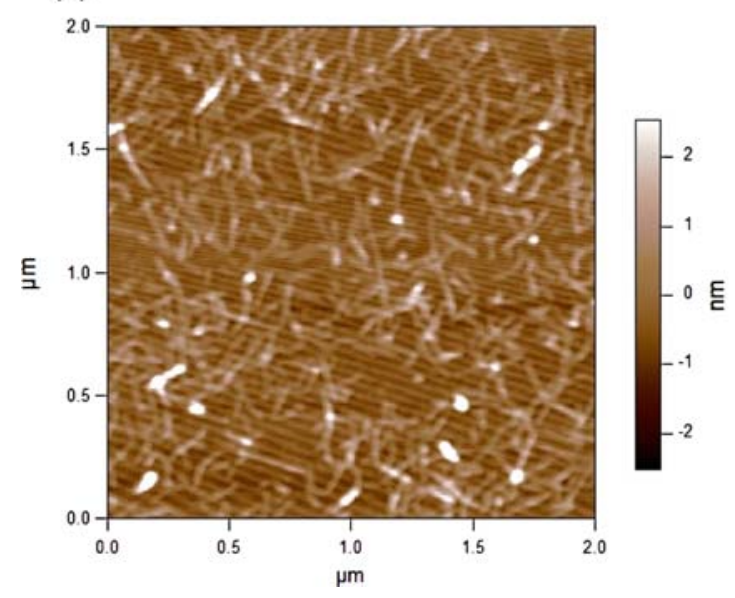

(b)

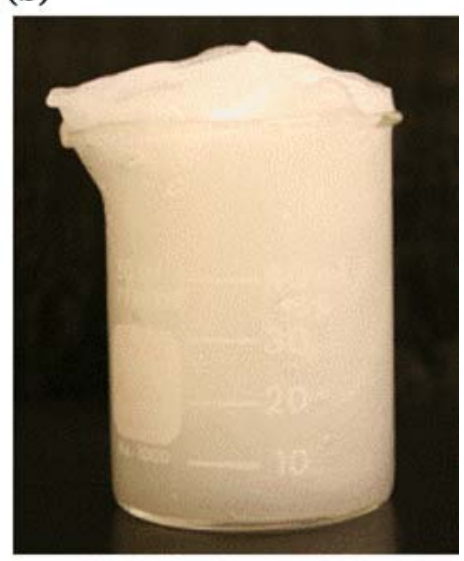




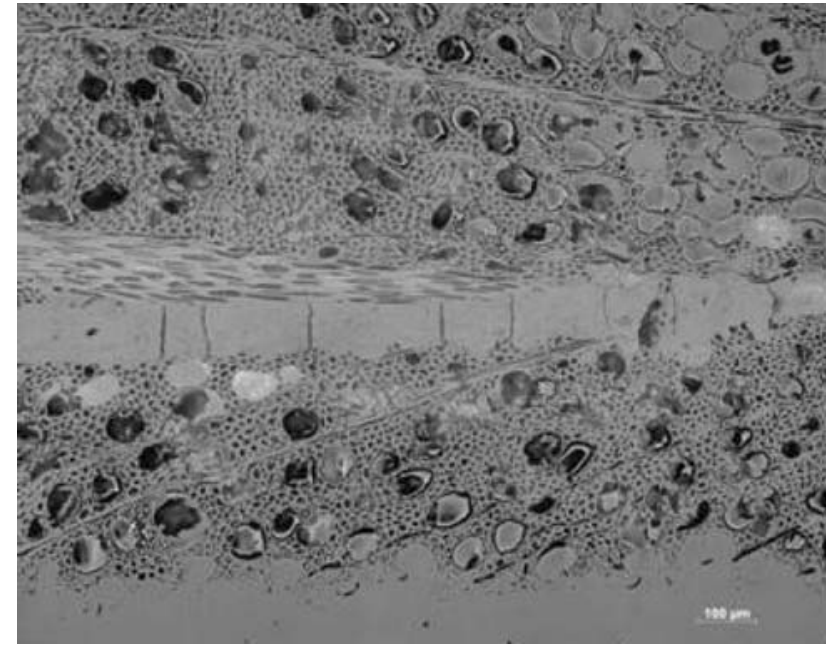

Fig. 14 Light microscope image of beech wood bonded with urea formaldehyde. Vertical cracks in the cured urea formaldehyde bond line are a typical result of the brittleness of this frequently used wood adhesive

A team led by Wolfgang Gindl and Josef Keckes on nanocellulose research has been investigating the reinforcement of adhesives. For this purpose, a 5\% suspension (cellulose/water) of dissolving grade beech pulp obtained from Lenzing R\&D was fibrillated by 20 passes through a laboratory refiner and, after diluting the suspension to $0.5 \%$ cellulose content, 10 passes through an APV-Gaulin highpressure homogeniser at a pressure of 450 bar. Thereafter, the suspension was vacuum-dried to increase the cellulose content to $3.2 \%$. A higher cellulose content would have been desirable in the wood adhesive, but this was limited by the rapidly increasing viscosity of the suspension with the decreasing water content. Lap-joint shear test specimens according to EN 302 [190] were prepared with beech wood using the following different adhesives:

- pure UF (W-Leim Spezial, Dynea);

- UF reinforced with untreated pulp fibres (5\% cellulose per unit weight cured UF);

- UF reinforced with homogenised pulp fibres (5\% cellulose per unit weight cured UF);

and tested to failure in a universal testing machine at a speed of $1.66 \times 10^{-5} \mathrm{~m} \mathrm{~s}^{-1}$. The overall deformation in the overlapping region of the EN 302 specimens was recorded by means of a Zwick Macrosense clip-on deformation sensor.

The results of the mechanical tests ( 9 specimens each) are shown in Fig. 15. With a shear strength of $10.3 \pm 0.9 \mathrm{MPa}$, the UF used in the present study is well within the range of bond strengths observed for a variety of wood adhesives in a previous study. The addition of $5 \%$ untreated pulp fibres had no significant effect on the shear strength, which was $9.9 \pm 0.8 \mathrm{MPa}$. In strong contrast, the addition of

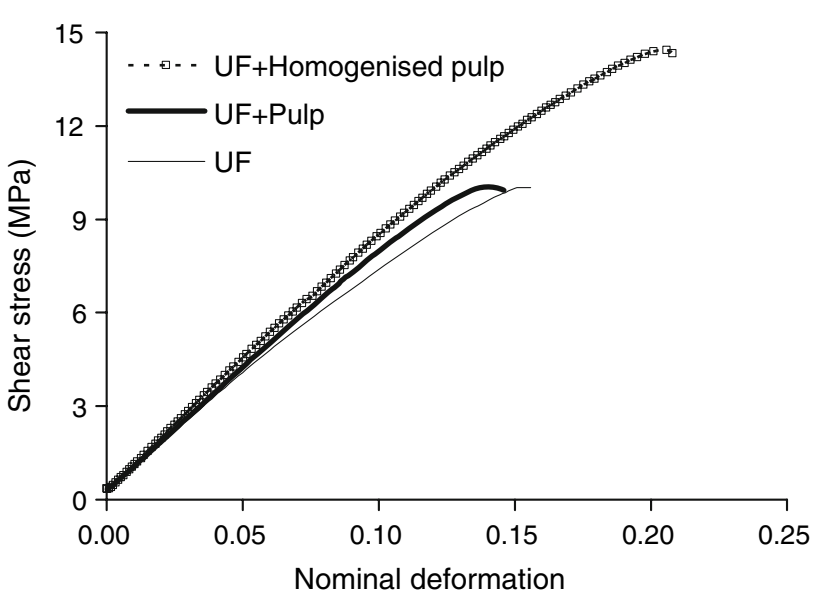

Fig. 15 Shear stress of different lap-joint specimens plotted over deformation (the deformation is only nominal because it comprises axial and shear contributions from both the wood and the adhesive)

5\% refiner-treated and high-pressure homogenised cellulose resulted in a significant increase of shear strength to a value of $13.8 \pm 1.4 \mathrm{MPa}$. The stress-strain curves shown in Fig. 15 indicate a significantly higher deformation at failure for the specimens reinforced with homogenised pulp fibres, suggesting that the UF adhesive was possibly toughened by the addition of fibrillated cellulose. This assumption is supported by the fact that cracks, which are frequent in conventional UF bond lines (Fig. 14), were not found when cellulose-reinforced UF was used.

The value of 13.8 MPa for the shear strength measured for cellulose-reinforced UF adhesive bonds is higher than the average shear strength of $10 \mathrm{MPa}$ observed for structural adhesives such as phenol-resorcinol-formaldehyde, melamine-urea-formaldehyde, and one-component polyurethane [187]. This indicates that the addition of fibrillated cellulose to UF significantly improves the mechanical performance of wood adhesive bonds, thus opening up new fields of application for UF, which is currently used only in the non-structural field.

Optically transparent cellulose nanocomposites for electronic displays (RISH, Kyoto University, Kyoto, Japan)

Flexibility is an essential characteristic not only for future electronic devices such as displays and solar cells, but also as materials suitable for roll-to-roll production processes. Roll-to-roll processing enables the continuous deposition of functional materials such as metal wiring, transparent conductive films and gas barrier films on a roll of optically transparent flexible plastics, allowing a simple and inexpensive processing suitable for the manufacture of flexible electronic devices. Most plastics however have a large 
coefficient of thermal expansion (CTE), of the order of $50 \mathrm{ppm} \mathrm{K}^{-1}$, and flexible plastics in particular exhibit extremely large CTEs exceeding $200 \mathrm{ppm} \mathrm{K}^{-1}$. Functional materials deposited on plastic substrates could therefore break or be damaged by the temperatures involved in the assembly and in the mounting processes due to the mismatch of the coefficients of thermal expansion from the different materials. Hence, the development of flexible transparent plastics with a low coefficient of thermal expansion, similar to glass $\left(8 \mathrm{ppm} \mathrm{K}^{-1}\right)$, is essential to realize roll-to-roll processing. In this context, the reinforcement of transparent plastics by nano-sized fibres is considered to be an ideal way, since elements with diameters less than one-tenth of the visible light wavelength are free from light scattering, allowing optically transparent composites.

Hiroyuki Yano and colleagues at RISH, Kyoto University, have demonstrated experimentally the advantage of nanoscale reinforcements using cellulose nanofibres (bundles of cellulose microfibrils) [26]. They obtained transparent composites by reinforcing various types of resins (Fig. 16a), even at fibre contents as high as $70 \mathrm{wt} \%$, using $\mathrm{BC}$ nanofibres $10 \mathrm{~nm}$ thick and $50 \mathrm{~nm}$ wide. Because $\mathrm{BC}$ nanofibres are bundles of semi-crystalline extended cellulose chains, the resulting nanocomposites are not only highly transparent, but also exhibit a low CTE comparable to silicon $\left(4 \mathrm{ppm} \mathrm{K}^{-1}\right)$ and mechanical strength comparable to mild steel. Due to the nanofibre size effect, high transparency was obtained against a wide distribution of resin refractive indices from 1.492 to 1.636 at $20^{\circ} \mathrm{C}$, being also less sensitive to refractive index variations caused by the elevation of ambient temperature up to $80{ }^{\circ} \mathrm{C}$ [191]. Moreover, they have succeeded in depositing an electroluminescent layer on these transparent $\mathrm{BC}$ nanocomposites, as shown in Fig. 16b.

They also reported that the addition of only $7.4 \mathrm{wt} \%$ of $\mathrm{BC}$ nanofibres, which deteriorated light transmittance by

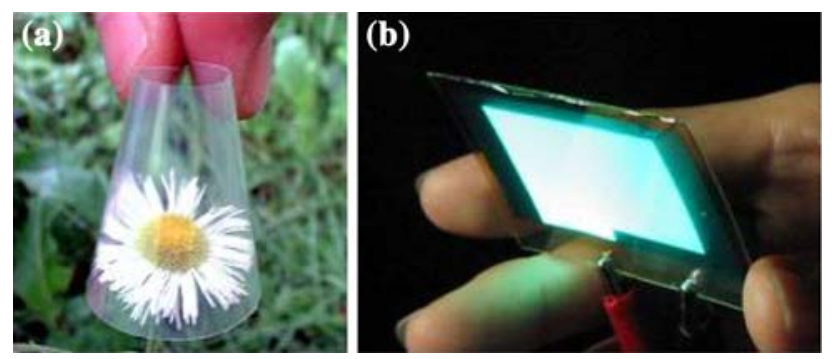

Fig. 16 a Flexible transparent nanocomposites reinforced with bacterial cellulose (BC) nanofibres and $\mathbf{b}$ luminescence of an OLED deposited onto the transparent $\mathrm{BC}$ nanocomposite. Reproduction of image a from [26] and b from [193] with permission from Wiley (ㄷ) Wiley 2005 and 2008) only $2.4 \%$, was able to reduce the CTE of an acrylic resin from 86 to $38 \mathrm{ppm} \mathrm{K}^{-1}$ [192]. Subsequently, they succeeded in the production of composites possessing an ultra low CTE of $4 \mathrm{ppm} \mathrm{K}^{-1}$ at a fibre volume fraction of $5 \%$ [193]. The flexibility and high thermal stability were attained by reinforcing a low Young's modulus transparent resin with low CTE and high modulus cellulose nanofibres forming an in-plane network layered structure of BC. In addition, they showed that acetylation significantly reduces the hygroscopicity of $\mathrm{BC}$ nanocomposites, while maintaining optical transparency and thermal stability [194, 195]. It was also demonstrated that acetylation prevents the thermal deterioration of the composites [194].

The successful reinforcement of transparent plastics with $\mathrm{BC}$ engendered a new interest in plant cellulose microfibrils. Iwamoto et al. [196] attempted the fibrillation of pulp fibres by using a grinding treatment. The grinding treatment resulted in the successful fibrillation of wood pulp fibres into nanofibres. However, repeated passes through a grinder to obtain uniform nanofibres caused a reduction in the crystallinity and degree of polymerisation of cellulose nanofibres, resulting in an increase in thermal expansion and a decrease in the mechanical properties of the composites [197].

In wood cell walls, the cellulose microfibril bundles of $12-16 \mathrm{~nm}$ in width exist encased by the embedding matrix. However, the drying process in typical pulp production generates strong hydrogen bonding between the bundles after the removal of the matrix, which makes it difficult to obtain thin and uniform cellulose nanofibres. Hence, Abe et al. [198] kept the material in the water-swollen state after the removal of the matrix, and succeeded in obtaining cellulose nanofibres with a uniform width of $15 \mathrm{~nm}$ using only one pass through the grinder (Fig. 17). Under these conditions, the CTE improved from $18 \mathrm{ppm} \mathrm{K}^{-1}$ of once-dried commercial pulp-based nanocomposites to $13 \mathrm{ppm} \mathrm{K}^{-1}$ of the never-dried pulp-based nanocomposites.

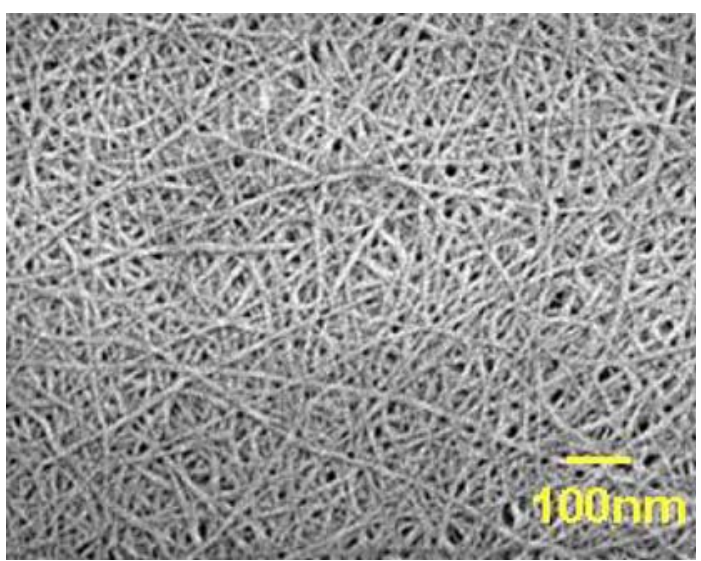

Fig. 17 Cellulose nanofibres obtained by a grinder treatment 
Following this pioneering work on never-dried pulp, Iwamoto et al. [92] studied the effect of hemicellulose on the nanofibrillation and mechanical properties of nanofibre reinforced composites, and reported that hemicelluloses act as inhibitors of the coalescence of cellulose nanofibres (microfibril bundles) during drying, and facilitate the nanofibrillation of once-dried pulp. Furthermore, hemicelluloses provide adhesion between nanofibres, contributing to the reduction of thermal expansion and enhancement of mechanical properties of the composites. Shimazaki et al. [90] also reported the excellent thermal conductivity of the cellulose nanofibre/epoxy resin composites.

Recently, Nogi et al. [199] developed what might be best described as an optically transparent paper. It is a foldable nanofibre material with low thermal expansion $\left(\mathrm{CTE}<8.5 \mathrm{ppm} \mathrm{K}^{-1}\right)$ consisting of $100 \%$ cellulose nanofibres (Fig. 18) with the same chemical constituents of traditional paper and also a similar production process. The only difference is in the fibre width and the size of the interstitial cavities or pores. The foldable, low CTE, and optically transparent nanofibre paper could be a perfect match as substrates for continuous roll-to-roll processing.

Cellulose microfibril-based nanocomposites for semistructural applications (RISH, Kyoto University, Kyoto, Japan)

The exploitation of cellulose nanofibrils to produce highstrength composites began by selecting wood samples with the highest modulus and strength based on the sound velocity along the specimens, impregnating them with a low molecular-weight phenolic resin and hot pressing at pressures of 30 to $50 \mathrm{MPa}$ [200]. As the resin acted as a plasticizer during compression and the curing fixed the deformed and densified conditions, Young's modulus and bending strength of the compressed wood achieved values around 40 $\mathrm{GPa}$ and $400 \mathrm{MPa}$, respectively. Later, to increase the

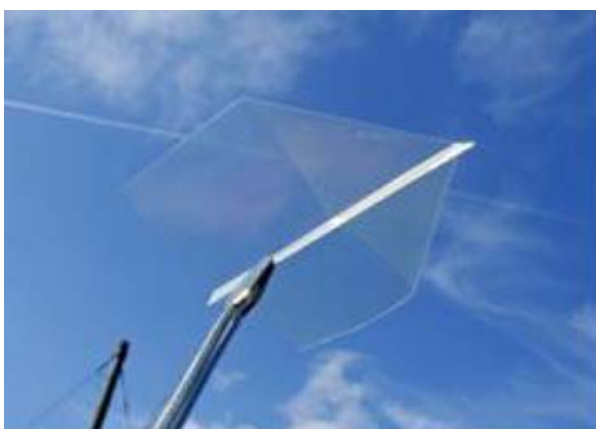

Fig. 18 The $100 \%$ cellulose nanofibre sheet is as foldable as traditional paper. Reproduction of image from [199] with permission from Wiley (c) Wiley 2009) cellulose nanofibril content, the matrix substances of wood veneers were removed by a mild chemical treatment [201]. The total weight was reduced by $30 \%$ and the combination of raw material selection and the removal of non-cellulosic constituents ultimately resulted in composites with a bending modulus of $62 \mathrm{GPa}$ and a strength of $670 \mathrm{MPa}$ [202]. Even though these materials could not be strictly called nanocomposites, they were based on the reinforcing potential of cellulose nanofibrils. Instead of disintegrating wood into individualized fibrils, the original structure of unidirectionally oriented fibres and fibrils of wood was preserved to achieve ultimate strength of the final composites.

The production of anisotropic materials based on cellulose nanofibrils extracted from wood, in a morphology known as MFC, was realized by molding MFC without any adhesive [203]. This material achieved a bending strength of $250 \mathrm{MPa}$. The addition of just $2 \mathrm{wt} \%$ oxidized starch doubled the yield strain, and the bending strength increased to $310 \mathrm{MPa}$. The initial water content of MFC, about 90 $\mathrm{wt} \%$, was slowly extracted while applying the moulding pressure, so the capillary forces of the intervening water being evaporated drew the nanofibrils together, connecting them by hydrogen bonds as the material dried.

Later on, sheets similar to paper obtained by filtration and drying of MFC slurries were impregnated with a phenol formaldehyde resin (PF), stacked in layers and compression moulded under pressures as high as $100 \mathrm{MPa}$ [32]. The mechanical properties obtained were substantial; a Young's modulus of $19 \mathrm{GPa}$ and a bending strength of about $370 \mathrm{MPa}$ at a fibre content around $10 \mathrm{wt} \%$. When the degree of fibrillation was varied from non-fibrillated pulp through MFC, it was found that there was no change in strength for composites prepared using pulp with fibrillation limited to the fibre's surface. A stepwise increase however occurred when a complete breakage and fibrillation of the cell wall of the fibres was achieved [88]. Microfibrillation eliminates defects or weaker parts of the original fibers that would act as the starting point of cracks, but also increases interfibrillar bond densities creating a structure that favours ductility. When compared to microcomposites made with non-fibrillated pulp fibres, MFC nanocomposites had a slightly higher Young's modulus, but exhibited significantly higher bending strength as a direct consequence of an enhanced strain at fracture. As reported in the section "Optically transparent cellulose nanocomposites for electronic displays (RISH, Kyoto University, Kyoto, Japan)", similar nanocomposites can and have been produced using BC. As a comparison to this material, the BC samples had a Young's modulus of 28 $\mathrm{GPa}$ and a bending strength in excess of $400 \mathrm{MPa}$ [204].

To increase the resin content and make cellulose-based composites less susceptible to degrading agents like water or moisture, yet averting the brittle nature of PF, MFC was 
mercerized with a strong $(20 \mathrm{wt} \%) \mathrm{NaOH}$ aqueous solution to verify its effectiveness on nanocomposites [205]. Alkali treatment is a proven process to enhance toughness in cellulose-based microcomposites [206, 207]. The composites with a resin content about $20 \mathrm{wt} \%$ exhibited a twofold increase in strain to failure compared to untreated MFC composites, with the same resin content. Young's modulus decreased slightly, but the bending strength remained practically unaltered due to the increased strain. Mercerization of MFC sheets caused an in-plane contraction, likely due to the contraction of the cellulose nanofibrils [208]. This, in turn, could be related to an entropy increase in less ordered regions along the nanofibril direction [209]. A possible explanation for the $\mathrm{NaOH}$ treated MFC composites' enhanced ductility might be the straightening of contracted amorphous cellulose molecules when under load.

As cellulose is a naturally occurring polymer, the use of a matrix resin equally bio-based has been also considered. To deliver good dispersion of nanofibres in PLA, the water in MFC was replaced by an organic solvent (acetone) and subsequently mixed with a fully amorphous grade PLA previously dissolved in the same solvent [210]. The mixture had the solvent extracted by evaporation, compounded by a kneader, and thin films were obtained by compression molding of the compounds. A $10 \mathrm{wt} \%$ MFC load resulted in modulus increase of $40 \%$ and strength gains of $25 \%$ over the neat PLA without a reduction in yield strain. In cellulose nanocomposites produced by film casting, the reinforcement is accomplished through the formation of a percolated network of nanofibres connected by hydrogen bonds [2, 65], but in compression moulding, such interactions are very limited [211, 212]. However, nanofibril bundles can produce networks by mutual entanglements [52, 213], resulting in similar reinforcing capability in moulded composites. Later, the method was extended to a semicrystalline grade of PLA [214], improving tensile modulus and strength in both amorphous and crystallized states, and also enhancing the heat resistance (storage modulus at high temperature), which was not possible with the fully amorphous PLA grade. More recently, an environmentally benign papermaking-like process, to obtain sheets from an aqueous suspension of cellulose nanofibres and PLA fibres and subsequent hot pressing a stack of the dried sheets, was proposed [215]. The method is quite simple with potential implementation at an industrial scale. A summary of the stress-strain behaviours from all of these materials is given in Fig. 19, with comparative data for a magnesium alloy (Mg alloy) and glass fibre reinforced plastic (GFRP). It is clear the mechanical properties exceed GFRP and are favourably compared with the Mg alloy, suggesting that they have great potential in low-weight engineering applications.

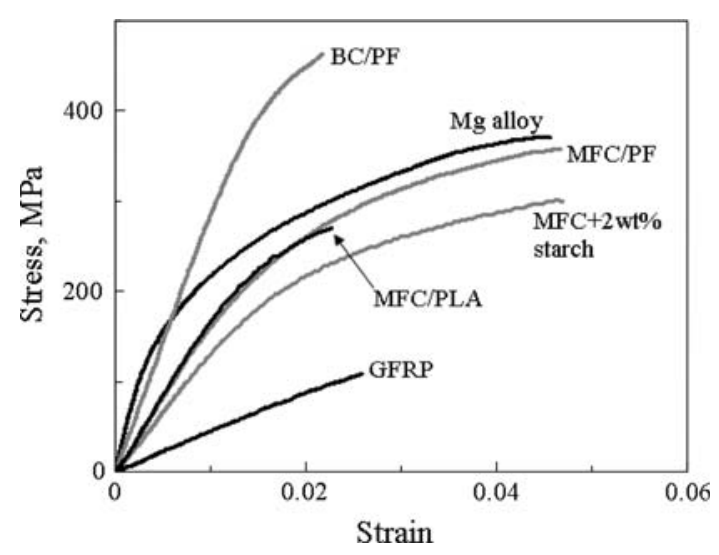

Fig. 19 Typical stress-strain curves of nanocomposites based on cellulose microfibrils compared with those of conventional highstrength materials; bacterial cellulose/phenol formaldehyde (BC/PF), magnesium alloy (Mg alloy), microfibrillated cellulose/phenol formaldehyde (MFC/PF), microfibrillated cellulose/poly(lactic acid) (MFC/PLA), microfibrillated cellulose/2 wt \% starch (MFC $+2 \mathrm{wt} \%$ starch) and glass fibre reinforced plastic (GFRP)

\section{Cellulose/DNA hybrid nanomaterials (Virginia Tech/ Oregon/Portland State University, USA)}

The fabrication of nanoscale devices is a challenging, but potentially important, technology that is currently the subject of a great deal of research and a little amount of progress [216-218]. Such nanoscale constructions utilizing a bottom-up approach to device building have many foreseeable applications in areas as diverse as miniaturized electronics, sensors, and biomedical devices. One of the most chemically versatile, abundant and inexpensive nanoparticles available for nanodevice development is the cellulose nanowhisker. Recent research on utilizing DNA oligomers to control the bonding of cellulose nanowhiskers has been undertaken by John Simonsen and co-workers. These proof of concept experiments set the stage for the pursuit of future developments in nanoscale devices through the utilization of low cost and chemically versatile cellulose nanowhiskers. Whilst not a composite per se the combination of cellulose nanowhiskers with DNA opens up the possibility of structuring biomaterial-based nanocomposites in the future through self-assembly methods.

Two different DNA oligomers were used in this study, a 20-mer: $\left\{5^{\prime}\right.$-aminoC6/GCT CTA CCT GAC TAG CTC GT- $\left.3^{\prime}\right)$ and its complement, and a 78 -mer: $\left\{5^{\prime}\right.$-aminoC12/ CAG TCA GAT CAG GAC ATG AGA TCA TGC TAG TCA GCT ACG GTC ACT GCT AGT CCG TAC GTA CCA TGT CAT AGT GTA GGT- $3^{\prime}$ \} and its complement.

The cellulose nanowhiskers were prepared by acid hydrolysis and then the C6 carbon was carboxylated using TEMPO oxidation [219]. FTIR transmission spectra of the carboxylated cellulose nanowhiskers confirmed the reaction. A carboxyl content of $1.73 \mathrm{mmol}$ of $\mathrm{CO}_{2} \mathrm{H}$ per gram 
of nanowhiskers (starting material) was calculated. This C6 carboxylate group was reacted with the amino group on the modified DNA oligomer via EDC-facilitated amide formation yielding DNA grafted cellulose nanowhiskers (DNA-g-nanowhiskers) [220, 221].

Both dynamic light scattering (DLS) and UV hyperchromicity of single strand and duplexed DNA were used to observe the combining of the DNA-g-nanowhiskers at low temperature and their separation, or "melting" at higher temperatures. Atomic force microscopy (AFM) was used to image the duplexed DNA-g-nanowhiskers.

Typical reported surface areas for cellulose nanowhiskers are $\sim 250 \mathrm{~m}^{2} \mathrm{~g}^{-1}$ [222]. At the highest grafting value $47 \mu \mathrm{mol} \mathrm{DNA} \mathrm{g}{ }^{-1}$ of nanowhiskers was achieved for the $\mathrm{C}_{12}$ oligomer. This gives an estimate of $\sim 9 \mathrm{~nm}^{2} / \mathrm{DNA}$ graft, which suggests a spacing of $\sim 3 \mathrm{~nm}$ between DNA backbone chains extending from the surface. Since the cross-sectional extent of a (duplexed) DNA molecule is on the order of $2 \mathrm{~nm}$ [223], there may be a crowding factor involved and the longer $\mathrm{C}_{12}$ modifier on the DNA oligomer may provide more flexibility for the graft, and thus accommodating a higher crowding factor.

The modelling equation for DLS assumes the particles are spherical. The cellulose nanowhiskers are not spherical, but DLS-derived hydrodynamic radius of the equivalent sphere was used as a rough marker to determine the extent of agglomeration of the needle-shaped whiskers.

Solutions of nanowhiskers functionalized with complementary oligonucleotides were mixed and hybridized (duplexed) in $0.1 \mathrm{M}$ phosphate buffer at $0.5 \mathrm{M}$ ionic strength for $12 \mathrm{~h}$. DNA-g-nanowhisker dispersions showed a substantial increase in hydrodynamic size (particle diameter) when compared to ungrafted carboxy-nanowhiskers and ssDNA-g-nanowhiskers.

Duplexed DNA-g-nanowhiskers were suspended in $0.1 \mathrm{M}$ phosphate buffer with $0.5 \mathrm{M}$ ionic strength at $75^{\circ} \mathrm{C}$ and then slowly cooled at a rate of $5 \times 10^{-3}{ }^{\circ} \mathrm{C} \mathrm{s}^{-1}$. The effective diameter of the duplexed particles was measured at $10^{\circ} \mathrm{C}$ intervals. As the temperature was reduced from 75 to $45^{\circ} \mathrm{C}$, the measured particle size increased significantly, indicating that the grafted oligomers were duplexing and agglomerating the cellulose nanowhiskers (Fig. 20). After 5 min the temperature was again raised to $75{ }^{\circ} \mathrm{C}$ without removing the sample from the instrument. The particle size decreased, indicating the duplexed oligomers were disassociating and the cellulose nanowhiskers spontaneously re-dispersed in the suspension. The particle size returned to its original number, indicating complete re-dispersion of the DNA-g-nanowhiskers with the completion of a full cycle of alternate cooling and heating. This indicates that duplex formation and the subsequent disassociation above the "melting temperature" $\left(T_{\mathrm{m}}\right)$ of the DNA are reversible.

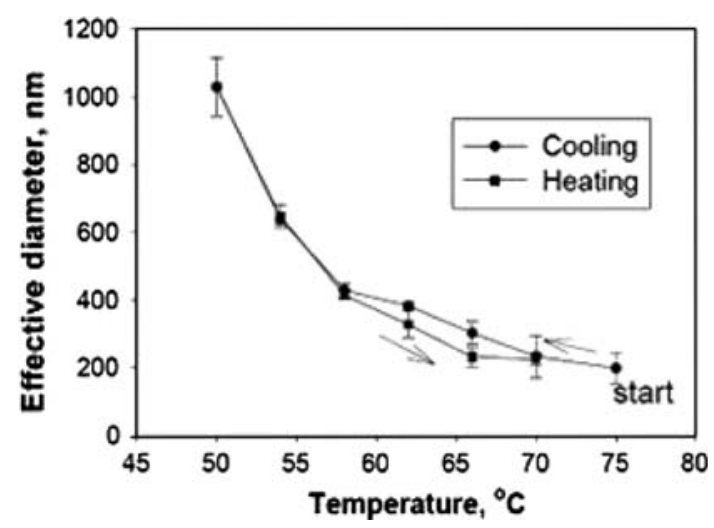

Fig. 20 DLS cycling data showing repeatable DNA duplex formation and melting with temperature. Reproduction of image from [219] with permission from American Chemical Society (ㄷ American Chemical Society 2009)

UV-vis spectroscopy was used to confirm the duplex formation and subsequent disassociation (typically called "melting") of DNA-g-nanowhiskers by tracking the hyperchromicity of the DNA duplex. As the complementary single-stranded DNA undergo duplexing, the extinction coefficient of the resulting double-stranded DNA (dsDNA) will be reduced. As a result, UV absorption of dsDNA (at $260 \mathrm{~nm}$ ) will be lowered. When the temperature is raised above the "melting" temperature $T_{\mathrm{m}}$ of DNA, the duplex should uncoil and the UV absorption should increase. Thus the formation and "melting" of DNA duplexes can be determined by measuring the absorption at $260 \mathrm{~nm}$ as a function of temperature. First, the UV absorption of the double-stranded DNA oligomers alone was recorded at $45{ }^{\circ} \mathrm{C}$. The temperature was gradually increased from 45 to $85{ }^{\circ} \mathrm{C}$ at a $0.03{ }^{\circ} \mathrm{C} \mathrm{s}^{-1}$ ramp rate, recording the absorption (at $260 \mathrm{~nm}$ ) in $3{ }^{\circ} \mathrm{C}$ intervals. The resulting "melting curves" of the oligomers showed a broad range from $\sim 60$ to $\sim 80{ }^{\circ} \mathrm{C}$. Next, the DNA-gnanowhiskers were cycled through a similar temperature range. The "melting" behaviour of the DNA oligomers grafted on the cellulose nanowhiskers was similar to that of the unbound oligomers (Fig. 21). This indicates that the grafting process did not affect the duplexing behaviour of the oligomers, i.e., their hyperchromicity. The observed "melting" behaviour in the UV-vis experiment was similar to the DLS experiment with the exception of the hysteresis in the UV-vis. It is thought that the hysteresis is due to the reaction time required for DNA to duplex. The temperature ramp rate in the $\mathrm{UV}$-vis experiment was $0.03{ }^{\circ} \mathrm{C} \mathrm{s}^{-1}$ while in the DLS experiment it was much slower, $5 \times 10^{-3}{ }^{\circ} \mathrm{C}$ $\mathrm{s}^{-1}$. Thus in the DLS experiment, the DNA had more time to duplex, or "melt" while in the UV-vis experiment, the faster temperature ramp rate resulted in a hysteresis effect. Together, the DLS and UV-vis results provide convincing 


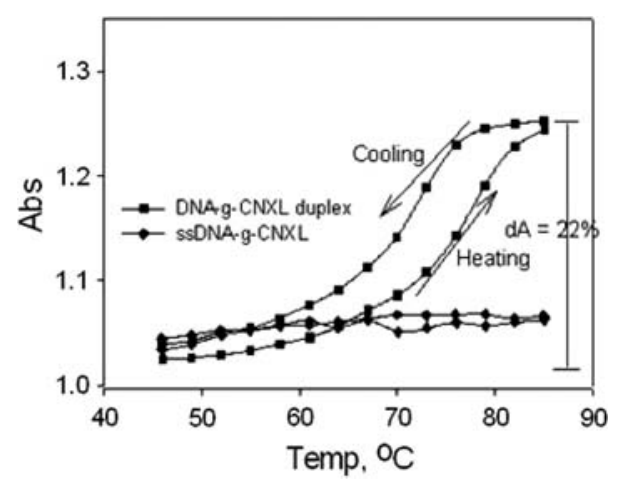

Fig. 21 UV cycling curve for cellulose nanowhiskers grafted with complementary strands of DNA oligomer. Reproduction of image from [219] with permission from American Chemical Society (C) American Chemical Society 2009)

evidence of the formation of a DNA/cellulose nanowhisker hybrid material via DNA duplex formation.

The morphology of the self-assembled DNA-g-cellulose nanowhisker duplex dispersion was examined using AFM.
Typical images (Fig. 22) indicate that duplexed DNA-gcellulose nanowhiskers formed branched structures whereas much looser and randomly distributed materials were observed in the images of control experiments with ungrafted or ssDNA-g-nanowhiskers (Fig. 22a). It is expected that the DNA-g-nanowhiskers when duplexed should exhibit strong side-to-side physical interaction due to hydrogen bonding between complementary DNA strands bonded on the nanowhisker surface. Side-to-side interactions between ssDNA grafted nanowhiskers are evident from the AFM images (Fig. 22b, d). One AFM image indicates a tendency of the DNA-g-nanowhiskers to interact end-to-end while duplexing (Fig. 22c), although both interaction schemes appear to be always present to some extent. This curious behaviour is puzzling and suggests further research is needed on this system. The side-to-side bonding is expected due to the grafting frequency of the DNA oligomers on the nanowhisker surface.

The end-to-end bonding may also be an artefact of the isolation procedure, since the imaged formations are dried from their aqueous dispersions. This behaviour of
Fig. 22 Duplexed DNA-gcellulose nanowhiskers formations dried from the aqueous dispersion and imaged using atomic force microscopy (AFM); a cellulose nanowhiskers grafted with single strand DNA. b Duplexed DNA-g-cellulose nanowhiskers at low magnification.

c, d Duplexed DNA-g-cellulose nanowhiskers at high magnification. Reproduction of image from [219] with permission from American Chemical Society (ㄷ American Chemical Society 2009)
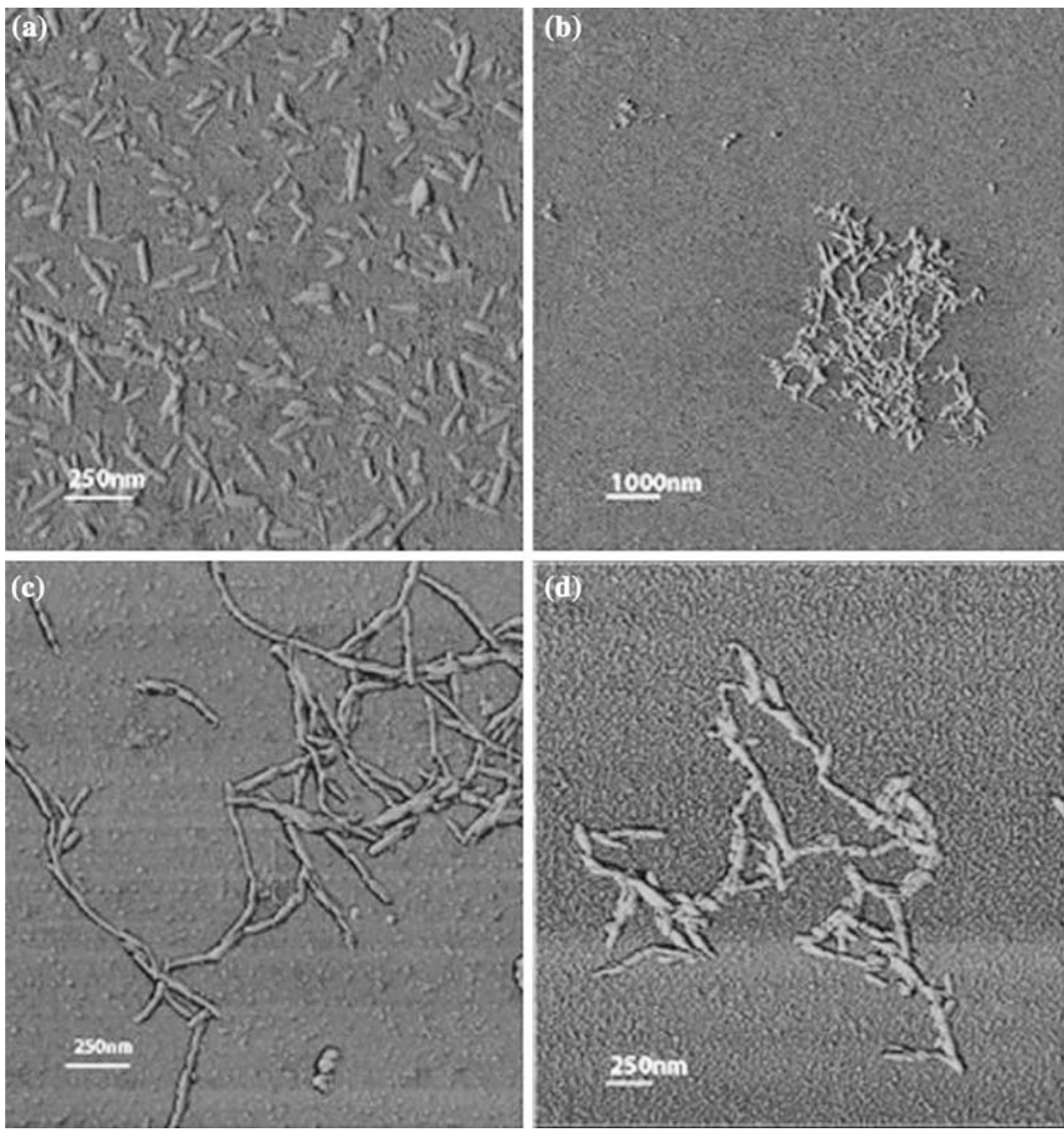
hybridized DNA-g-nanowhiskers requires additional investigation. However, this initial study sets the stage for further utilization of DNA to provide ordered structures of cellulose nanowhiskers with potential applications, including as scaffolding for tissue engineering applications.

\section{Hierarchical cellulose nanocomposites (Imperial College London, UK)}

Natural nanofibres are already being considered for numerous composite applications [44, 224]. Advantages of natural fibres are their low cost, low density, renewability and biodegradability. The main drawbacks are their dimensional inconsistency and variability in mechanical properties, relatively low tensile strength and their limited thermal stability, which limits the number of matrices that can be reinforced by natural fibres [225]. Simple natural fibre reinforcement of renewable polymers has thus failed to achieve the performance of conventional composite materials, such as glass fibre/polypropylene. New renewable reinforcing agents such as BC fibrils produced by bacteria belonging to the genera Acetobacter, Agrobacterium, Alcaligenes, Pseudomonas, Rhizobium or Sarcina may provide a breakthrough for composite applications [21]. BC fibrils have diameters ranging from 10 to $100 \mathrm{~nm}$ [226]. Studies of the properties of BC have shown that it has a high Young's modulus of up to $138 \mathrm{GPa}$ [10, 22, 23], a tensile strength of $2 \mathrm{GPa}$ and thermal expansion of only $0.1 \times 10^{-6} \mathrm{~K}^{-1}$, which are extremely attractive for applications as reinforcement in composites [21, 26]. The measured Young's modulus of BC is comparable to or even exceeds that of glass fibres but at a lower density. In addition to its light-weight and attractive mechanical properties, BC is non-toxic, renewable and biodegradable.

Commonly used natural fibre composite processing methods, such as blending, extrusion and even solvent casting/impregnation, have significant disadvantages when used for the preparation polymer nanocomposites containing anisotropic reinforcements. The introduction of BC, as with any other anisotropic nano-sized filler/reinforcement, into a polymer by extrusion unavoidably raises the viscosity of the polymer melt. Moreover, the processing conditions must be controlled to prevent the very hydrophilic cellulose whiskers transporting water into the hightemperature processing zone, which will lead to the premature degradation of the polymer (especially in the case of PLA) and degradation of the whiskers themselves can occur at $>180{ }^{\circ} \mathrm{C}$.

So far the progress in (scalable) manufacturing of renewable nanocomposites has been limited, and the properties of cellulose nanofillers in the composite have still to be satisfactorily utilised; the blocks hindering progress are principally in achieving good distribution or percolation of the nanoreinforcement throughout the matrix. Nature uses hierarchical structures in plant cell walls, shells and bones when high mechanical properties are required. The application of such a concept is markedly improving the engineering of truly green composites [227]. In an attempt to distribute the anisotropic BC in a polymer matrix and to use conventional processing techniques Juntaro et al. [27, 29] and Pommet et al. [30] created hierarchical structures in natural fibre composites by cultivating cellulose-producing bacteria in the presence of natural fibres (Fig. 23), such as sisal and hemp, resulting in the coating of natural fibre surfaces by BC. It was found that the strong and highly crystalline $\mathrm{BC}$ fibrils preferentially attached, in fact coated, the natural fibres thereby creating "hairy fibres" (Fig. 24) leading to a nanostructured natural fibre surface. Simply weighing the fibres before and after the $\mathrm{BC}$ fermentation process confirmed that between 5 and $6 \mathrm{wt} \%$ of $\mathrm{BC}$ adhered to the fibres after the modification. The strength of attachment of the nanocellulose coating to the natural fibres can be attributed to strong hydrogen bonding between the hydroxyl groups present in $\mathrm{BC}$ and the (ligno)cellulose in natural fibres [228].

The modification process did not affect the mechanical properties of sisal fibres but it significantly reduced the mechanical properties of hemp fibres. The exposure of the hemp fibres to the bacterial culture caused a drastic loss of fibre strength $(286 \pm 31 \mathrm{MPa}$ for original hemp and $171 \pm 11 \mathrm{MPa}$ for the BC coated hemp) as well as
Fig. 23 a Sisal fibres in bacterial cellulose fermentation medium before bacterial cellulose culture and $\mathbf{b} 2$ days after bacterial cellulose culture. Reproduction of images $\mathbf{a}$ and $\mathbf{b}$ from [30] with permission from the American Chemical Society (C) American Chemical Society 2008)
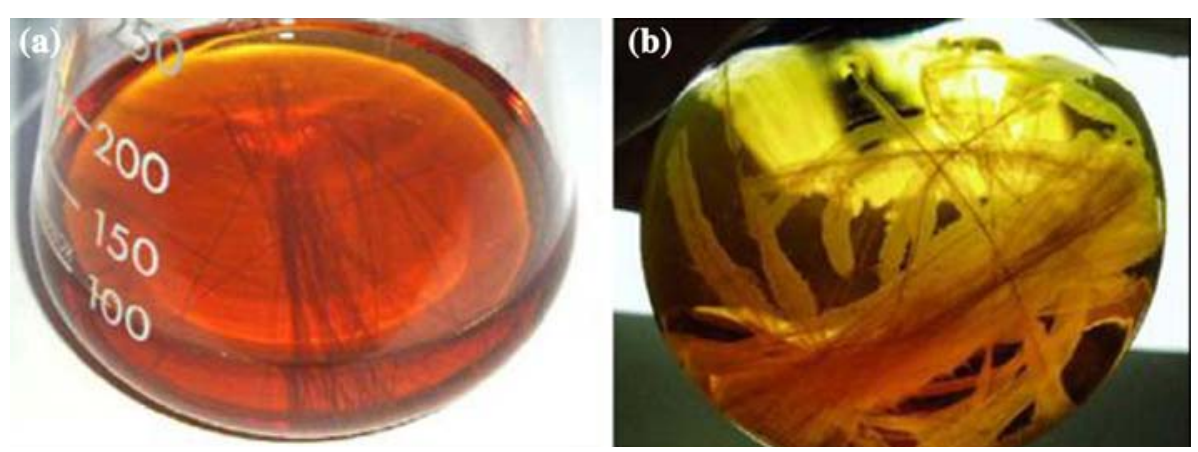
Fig. 24 Typical SEM

micrographs of sisal fibre without bacterial cellulose (left) and with bacterial cellulose attached (right). Reproduction of images from [30] with permission from the American Chemical Society (ㄷ) American Chemical Society 2008)
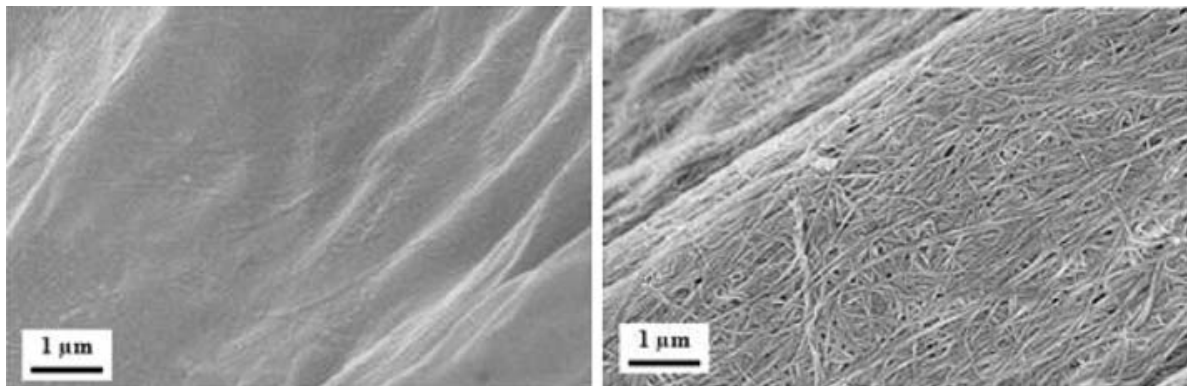

Young's modulus (Young's modulus decreased from $21.4 \pm 2.0$ to $8.8 \pm 0.7 \mathrm{GPa}$ for the original hemp and the $\mathrm{BC}$ coated hemp, respectively), which was due to a further separation (or brooming) of the hemp fibres in to smaller individual fibres as a result of the intrinsically non-cohesive structure of bast fibres.

The "hairy" characteristic of the BC coated sisal and hemp fibres helped to enhance the adhesion, as measured using single fibre pull-out tests [229], between natural fibres and cellulose acetate butyrate (CAB) and PLA. The apparent interfacial shear strength, as a practical measure of the interfacial adhesion, between sisal and CAB and PLA increased by 46 and $21 \%$, respectively, while the apparent interfacial shear strength between hemp and CAB increased as much as $140 \%$ [27]. This increase in the apparent interfacial shear strength is likely to be due to enhanced mechanical interlocking [27] in addition to the increased surface free energy of the BC coated (sisal) fibres (from $38.4 \mathrm{mN} \mathrm{m}^{-1}$ for original sisal to $61.9 \mathrm{mN} \mathrm{m}^{-1}$ for $\mathrm{BC}$ coated sisal), leading to better wetting of the fibres by the matrix $[28,30]$.

These "hairy" fibres deliver the nanoreinforcement into polymer matrices and avoid troublesome processing issues, such as increased melt viscosity, self-filtration and therefore gradient formation of the nanofiller as well as aggregation, associated with anisotropic nanofillers [230]. Coating natural fibres with $\mathrm{BC}$ also facilitates good distribution of the nanofibres within the matrix in the areas where the nanoreinforcement is required, i.e. near the conventional reinforcing micrometre-sized fibres. The improved interfacial adhesion enhanced the stress transfer efficiency between the fibres and matrix and thus resulted in an improvement in the mechanical and thermal performances of composites. Model unidirectional natural fibre reinforced nanocomposites [29] and short fibre nanocomposites [231] were manufactured via compression moulding to investigate the impact of the $\mathrm{BC}$ coating on composite mechanical properties. Note that fibres of sisal grafted with $\mathrm{BC}$ show improved composite properties in both $\mathrm{CAB}$ and PLA matrices over the unmodified sisal fibres, while the mechanical properties of composites made with BC grafted hemp fibres remain the same as for composites containing unmodified hemp even though the hemp fibres have far worse mechanical properties. For the unidirectional sisal fibre reinforced composites, both the tensile properties parallel and perpendicular to the fibre alignment were found to increase significantly when containing fibres with $\mathrm{BC}$ coating. In the case of modified sisal reinforced PLA, the parallel strength and Young's modulus increased by 44 and $42 \%$, while the off-axis strength and Young's modulus increased by 68 and 49\% [29], respectively. The $\mathrm{BC}$ coating technique also manifested improvements in some short fibre composites. It was found that the BC modification led to an increase of the crystallinity of PLA-based composites, as well as the improvements in tensile and flexural properties of short sisal fibrereinforced composites [231]. The presence of the nanofibrils improved the interfacial adhesion between the micrometre-sized reinforcing fibres and the polymer as confirmed by microscopy observations of the composite fracture surface (Fig. 25). The nanofibrils may also contribute to the direct reinforcement of the composites. The tensile and flexural properties of the short fibre composites were higher than commercial polypropylene compounds used in interior automotive part applications, indicating its potential in the automotive industry. Some short fibre composites also have comparable tensile and flexural properties to polypropylene reinforced with $20 \mathrm{wt} \%$ short glass fibre. Therefore, it can be concluded that hierarchical natural fibre composites (or natural fibre reinforced nanocomposites) are a very promising material to replace conventional plastics.

Nevertheless, there are many outstanding issues in hierarchically structuring composites which still need to be addressed; especially the compatibility between the lignocellulosic fibres, $\mathrm{BC}$ coating and the polymer matrices, the arrangement of the nanofibres within the composite, and the control of biodegradability of the final composite. Furthermore, the separation of end-of-life waste of truly green composites from the waste streams and compositing is another major issue requiring further research.

Novel materials based on cellulose nanofibres (KTH, Stockholm, Sweden)

Lars Berglund and co-workers have been developing a number of novel materials based on cellulose nanofibres, 
Fig. 25 SEM micrographs of interfacial failure between PLA and sisal fibre without bacterial cellulose (left) and with bacterial cellulose attached (right). Reproduction of images from [27] with permission from Wiley (c) Wiley 2008)
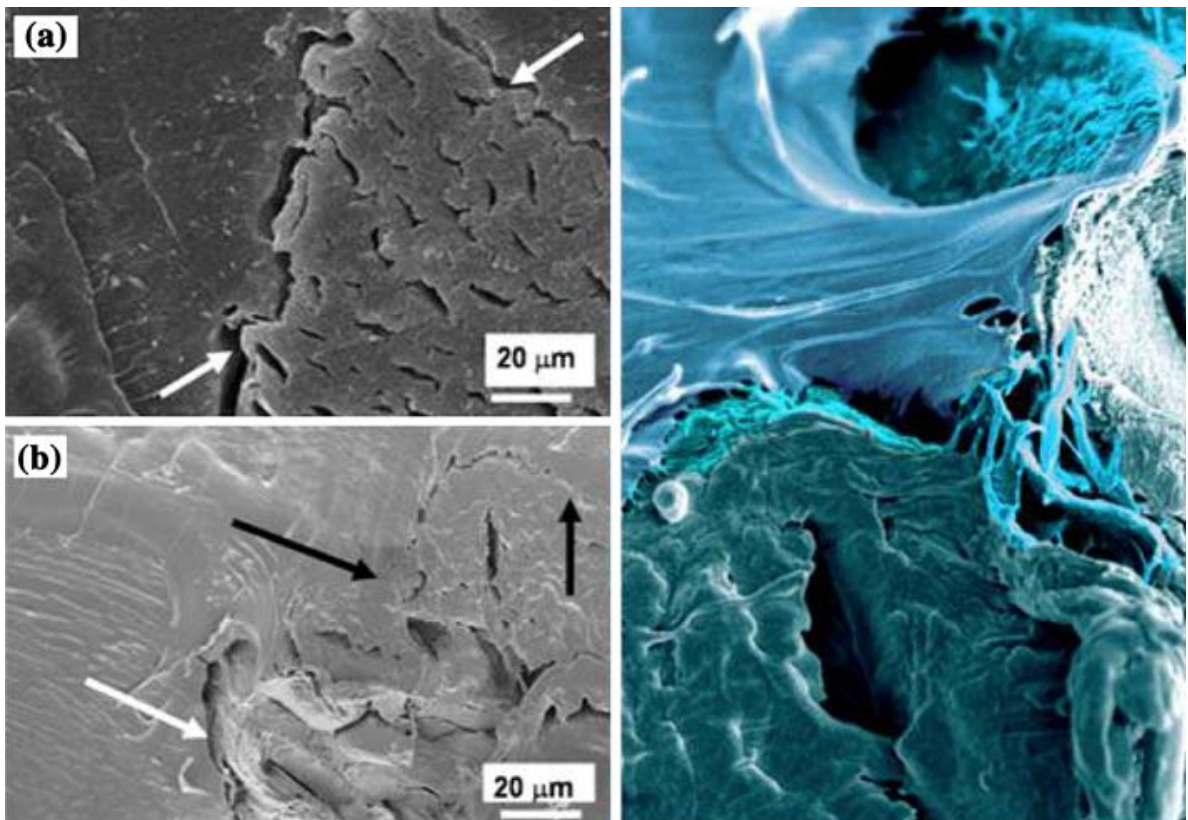

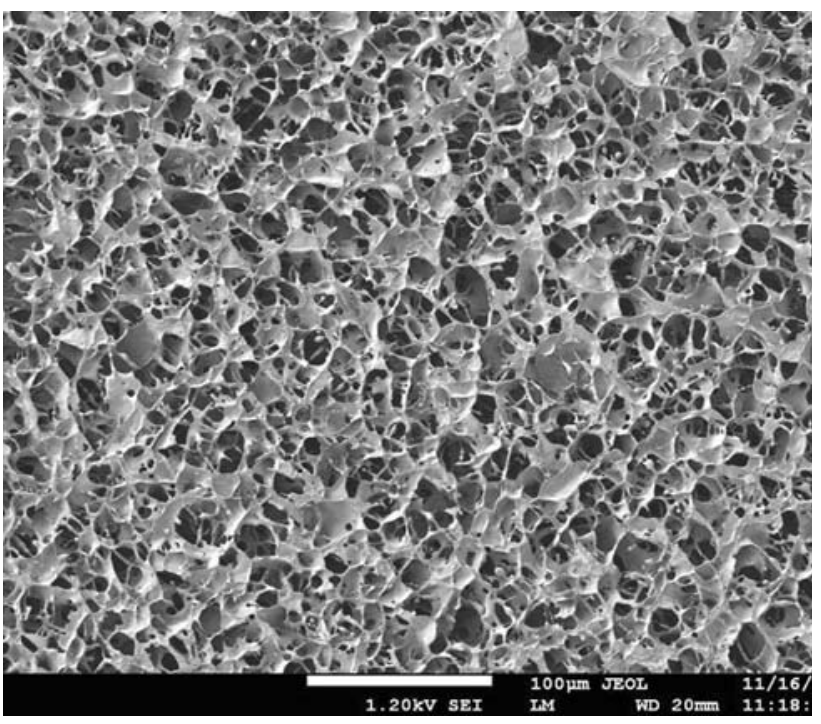

namely, foams and aerogels, nanopaper and starch-nanocellulose composites.

Polymer foams are of interest in many applications. Often, the mechanical performance is important, for instance in packaging materials for energy absorption and when used as core materials in sandwich structures for weight saving and insulation. Although fibre reinforced polymer foams are used, conventional reinforcing fibres have diameters at the typical scale of $10 \mu \mathrm{m}$. Since the typical cell wall thickness of polymer foams is a few micrometres, it means that microscale fibers are not suitable for cell wall reinforcement. However, it is possible to therefore use cellulose nanofibres as cell wall reinforcements. Svagan et al. [33] prepared biofoams based on amylopectin-rich potato starch and cellulose nanofibres from wood pulp. Water suspensions were prepared from dissolved starch mixed with well-dispersed cellulose nanofibres. The mixtures were frozen and the water was then removed by sublimation in the drying stage. The resulting biofoams were bioinspired in structure, since the cell walls contained a cellulose nanofibre network and a biopolymer matrix, as in plant cell walls. A typical field emission gun scanning electron microscope (FE-SEM) image of one of these foams is shown in Fig. 26, showing clearly the open walled structure. The cell wall compositions, with between 10 and 40 percent by weight of cellulose nanofibres, showed dramatic improvement in energy absorption during compressive loading. The absorbed energy was doubled as compared with the neat amylopectin reference, with 40 percent by weight of cellulose nanofibres. This novel material concept of cellulose nanocomposite biofoams is of interest in biomedical applications as
Fig. 26 FE-SEM micrograph of bioinspired starch-cellulose nanocomposite foam. The cellulose content is $40 \mathrm{wt} \%$, and the cellulose nanofibres are reinforcing the cell walls of the foam. Image by Dr. A. Svagan, Wallenberg Wood Science Center, Royal Institute of Technology, Sweden

well as in packaging material applications (expanded polystyrene replacement) and sandwich foam cores.

Aerogels are a new class of materials of great interest, not only for catalysis applications but also in structures for liquid storage. They also have exceptional thermal insulation properties. In the study by Pääkkö et al. [232] in Prof. Ikkala's group at Helsinki University of Technology, mechanically robust aerogels were prepared by freezedrying of cellulose nanofibre water suspensions. Ceramic 
aerogels, as well as neat polymer aerogels, are brittle in character. However, thin native cellulose aerogels can be folded back and forth without fracture. Furthermore, native cellulose aerogels can also be functionalized by subsequent treatment, i.e. by coating with conducting polymers [232].

Cellulose nanofibril suspensions can also be converted to nanopaper structures. In the study by Henriksson et al. [233], the remarkable potential of such nanopaper was demonstrated. A typical AFM image of the structure of this nanopaper is shown in Fig. 27. Exceptional mechanical performance was observed for the resultant nanopaper by selecting high molar mass cellulose, using nanofibrils with a surface charge, and by the use of a preparation procedure further favoring good dispersion. In particular, the work-tofracture was very high due to a strain-to-failure approaching $10 \%$, with a strength of more than $220 \mathrm{MPa}$ in uniaxial tensile experiments on large specimens. The yield stress is just above $100 \mathrm{MPa}$, followed by a region of linear strainhardening until fracture. In the strain-hardening region, nanofibrils must be slipping and bending in order to explain the large strain-to-failure. Young's modulus, as measured by loading-unloading experiments, also actually increased in the strain-hardening region.

The ability of cellulose nanopaper to maintain its integrity at high strains is demonstrated in the study by

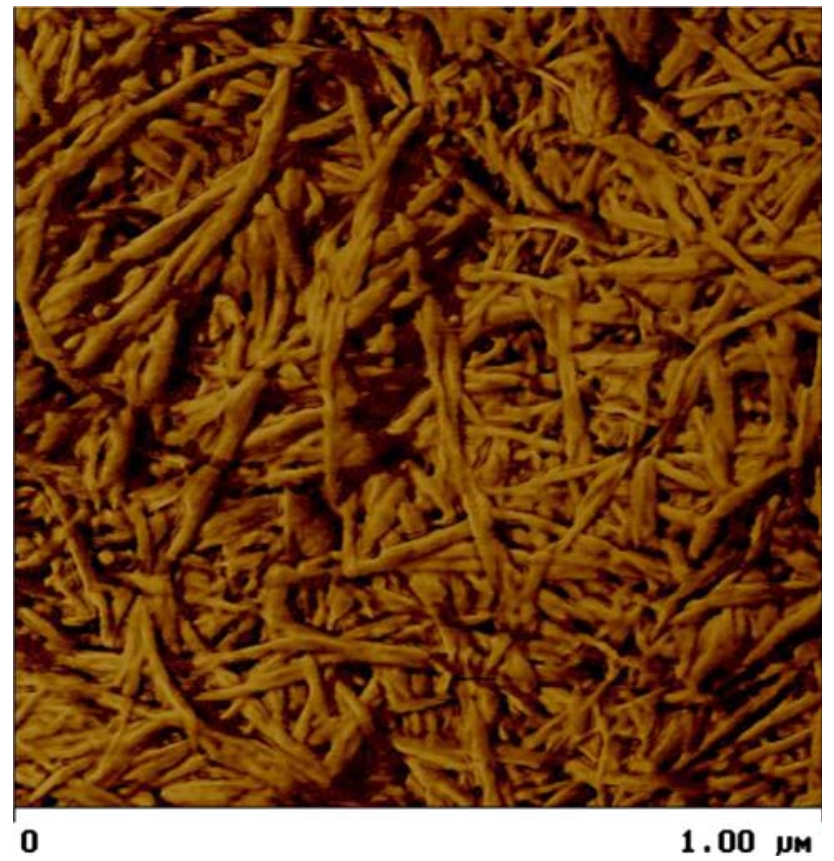

Fig. 27 AFM micrograph of cellulose nanopaper surface. The cellulose nanofibers are disintegrated from dissolving wood pulp of $95 \mathrm{wt} \%$ cellulose content, using an enzymatic pretreatment procedure. Image by Prof. I. Mondragon, University of Basque Country, San Sebastian, Spain
Svagan et al. [33]. The polymer matrix was highly glycerolplasticized amylopectin (50/50 composition). Such a matrix has almost viscous characteristics at room temperature, and still the nanocomposite with $60 \mathrm{wt} \%$ cellulose can have a tensile strength approaching $140 \mathrm{MPa}$, a Young's modulus of $6 \mathrm{GPa}$ and a strain-to-failure exceeding $6 \%$. If the moisture diffusion characteristics of starch are considered, addition of cellulose nanofibrils leads to remarkable improvements [234]. One important reason is the constraining effect of the cellulose nanopaper network on starch expansion due to moisture adsorption.

All-cellulose nanocomposites (Queen Mary, London, UK)

Alternative routes to environmentally friendly polymer composites have recently also focussed on approaches following mono-material-based eco-design concepts; so-called "all-polymer composites" or "self-reinforced polymer composites". For example, fully recyclable all-polypropylene (all-PP) or self-reinforced polypropylene (SR-PP) composites have been proposed to replace traditional glass fibre reinforced plastics for a number of applications, notably the automotive industry [235-241]. Following the success of these all-PP composites, all-cellulose composites have recently been introduced. In a similar fashion to allpolymer composites two different types of approaches can be followed for the creation of such self-reinforced cellulose composites: (i) conventional impregnation methods of cellulose matrix into cellulose fibres and (ii) novel selective dissolution methods where the cellulose fibre skins are partially dissolved to form a matrix phase that bonds fibres together.

The impregnation method has been used to create allcellulose composites based on ligno-cellulose fibres such as ramie [242, 243], rice husk [244], BC [245] and cellulose nanowhiskers [51]. Nishino and co-workers [242, 243] created all-cellulose composites in which both the fibres and matrix are cellulose, by distinguishing the solubility of the matrix cellulose into the solvent from that of the fibres through a pre-treatment of the fibres. Natural cellulose can be dissolved into $N, N$-dimethyl acetamide (DMAc) containing $\mathrm{LiCl}$ through the coordination of $\mathrm{Li}$ ions to the hydroxyl groups of cellulose. However, pre-treatment is needed for dissolution.

Various studies have reported the manufacture of allcellulose composites using partial dissolution of cellulose fibres. During composite preparation, rather than selectively melting fibre surfaces as in the case of thermoplastic all-PP composites [235, 236, 246-249], here the surface layer of cellulose fibres is partially dissolved to form the matrix phase of the all-cellulose composites. Meanwhile, the remaining cellulose fibre cores maintain their original 


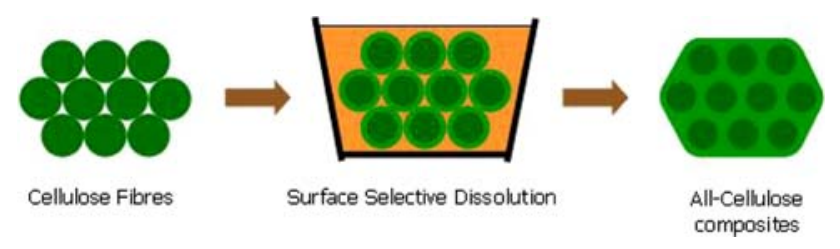

Fig. 28 Schematic model of fibre and composite cross-section for the preparation of all-cellulose composite with partially dissolved fibres [263]. Reproduction of image from [263] with permission from Elsevier (@ Elsevier 2008)

structure and impart a reinforcing effect to the composite (Fig. 28). This method constitutes not only a simplification of the composite's preparation, but also provides a significantly improved fibre/matrix interface. The surface selective dissolution method results not only in very high fibre volume fractions but also in a gradual change in properties of the fibre, forming an interphase or interfacial region which minimises voids and stress concentrations as in sharp, well-defined fibre/matrix interfaces.

The concept of all-cellulose composites has been explored for a wide range of cellulose materials including wood pulp fibres [250, 251], filter and Kraft paper [252255], MCC [256-260], sisal [261, 262], ramie [263], regenerated cellulose (Lyocell) and cellulose fibres spun from an anisotropic phosphoric acid solution (Bocell) [264], and BC [265]. These studies showed great promise. For example, in the case of plant cellulose fibres (ramie) exceptionally high properties were obtained using $\mathrm{LiCl} /$ DMAc as a solvent. Unidirectional composites with Young's modulus of around $30 \mathrm{GPa}$ and tensile strengths of $550 \mathrm{MPa}[242,243]$ were created (compared to a pure fibre strength of $700 \mathrm{MPa}$ ). As such, these composites sometimes out-performed those of traditional natural fibre composites by a factor of two and are among the highest ever reported for a natural fibre-reinforced composite [266-273]. In fact, as the process relies on selective dissolution of the outer fibre skins, the process works extremely well with natural cellulose, where the outer layers of the fibres, which are dissolved, mainly consist of disordered cellulose, while the core, which remains, consists of highly oriented cellulose [274, 275].

All-cellulose nanocomposites based on MCC [256-260] and $\mathrm{BC}$ [265] have also been prepared by these methods. Figure 29 shows the microstructure of a BC sheet and a BC composite sheet prepared by Soykeabkaew et al. [265] using the selective dissolution method. In the case of BC, optimum processing conditions using $\mathrm{LiCl} / \mathrm{DMAc}$ as a solvent allowed for the preparation of nanocomposites with tensile strengths of $410 \mathrm{MPa}$ and Young's moduli of 18 $\mathrm{GPa}$. Depending on the processing time, the sheets showed also remarkable high toughness characteristic possessing a work-of-fracture as high as $16 \mathrm{MJ} \mathrm{m}^{-3}$. Interestingly, compared to the all-cellulose nanocomposites prepared by partial dissolution of MCC powder of Gindl and Keckes [256] and the nanopaper prepared from cellulose nanofibrils by Henriksson et al. [233], BC nanocomposites exhibit nearly twice the tensile strength, while similar high values of work-to-fracture can be obtained. Figure 30 shows the stress-strain curves of these BC nanocomposites, where with increasing immersion time, after an initial small increase in strength, an obvious reduction in the composites' tensile properties is apparent. In light of these results it is interesting to compare these data for nano-size cellulose fibres with all-cellulose composites based on micron-sized cellulose fibres. Nishino and Arimoto [252] developed an isotropic all-cellulose composite using filter paper as a cellulose source. Unlike BC nanocomposites, these all-cellulose microcomposites showed a strong improvement in tensile strength with immersion time (almost five-fold increase in strength from 50 to $240 \mathrm{MPa}$, Fig. 30b). In comparison to BC, filter paper consists of a loosely formed, much weaker, micro-size cellulose fibre network with the appearance of larger voids and less hydrogen bonded fibre-fibre interactions. After the surface selective dissolution process, these voids are filled with cellulose matrix leading to a stronger interface and better stress transfer capability and as a result a marked increase in strength of the all-cellulose composite sheet. Again the mechanical properties of these all-cellulose composites are
Fig. 29 Scanning electron micrographs of the sheet surface of bacterial cellulose (BC) (left) and all-cellulose nanocomposites prepared with $\mathrm{BC}$ at an immersion time in $\mathrm{LiCl} / \mathrm{DMAc}$ of 20 min (right). The length of the scale bar is $1 \mu \mathrm{m}$ [265]. Reproduction of images from [265] with permission from Springer (C) Springer 2009)
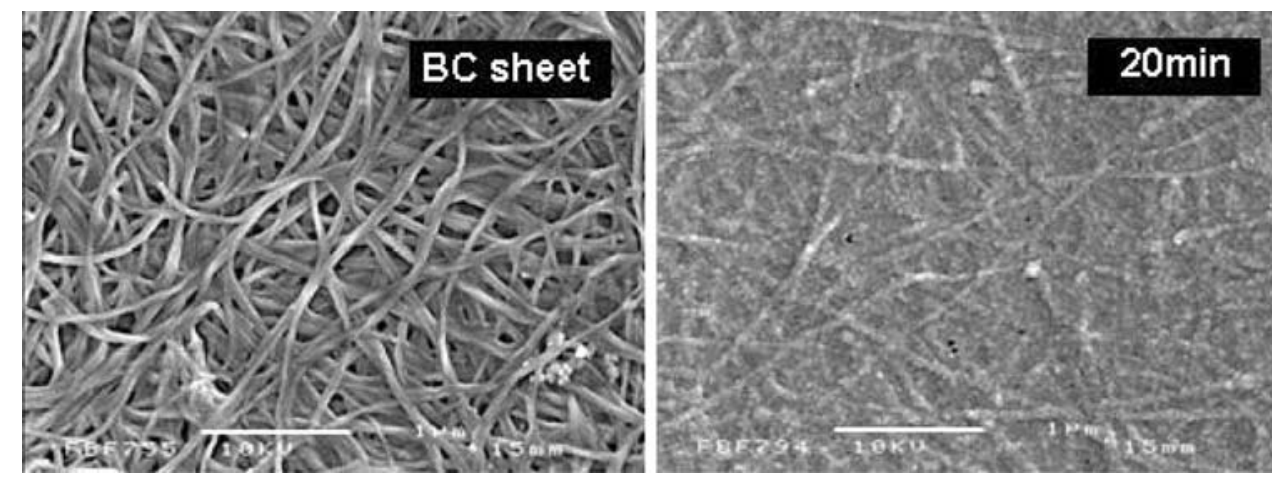

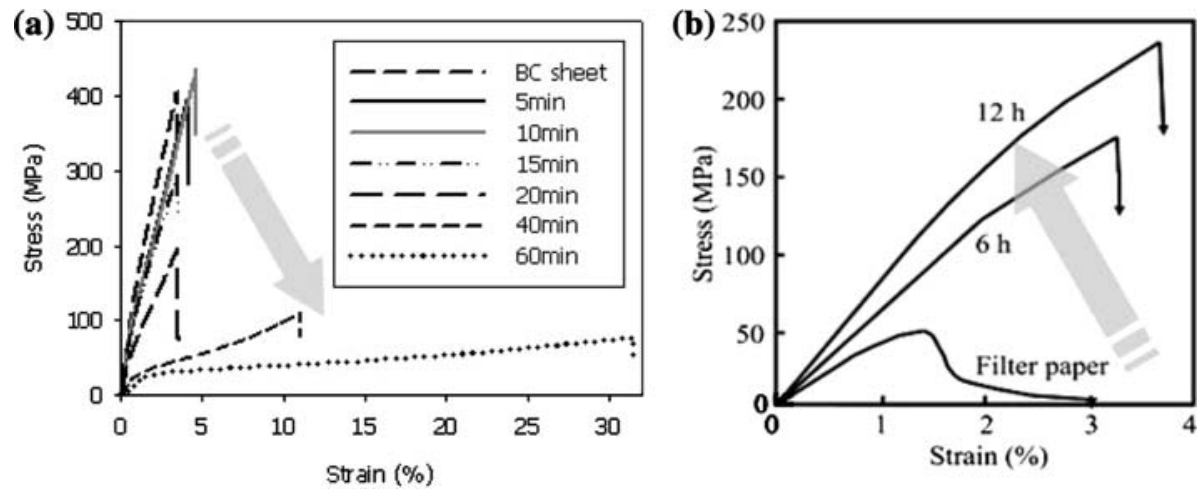

Fig. 30 Stress-strain curves of a bacterial cellulose (BC) sheet and all-cellulose composites prepared with nano-size bacterial cellulose at various immersion times [265] and b all-cellulose composites prepared with micro-size cellulose fibres of filter paper [252].

Reproduction of image a from [265] with permission from Springer (C) Springer 2009) and b from [252] with permission from the American Chemical Society (C American Chemical Society 2007)

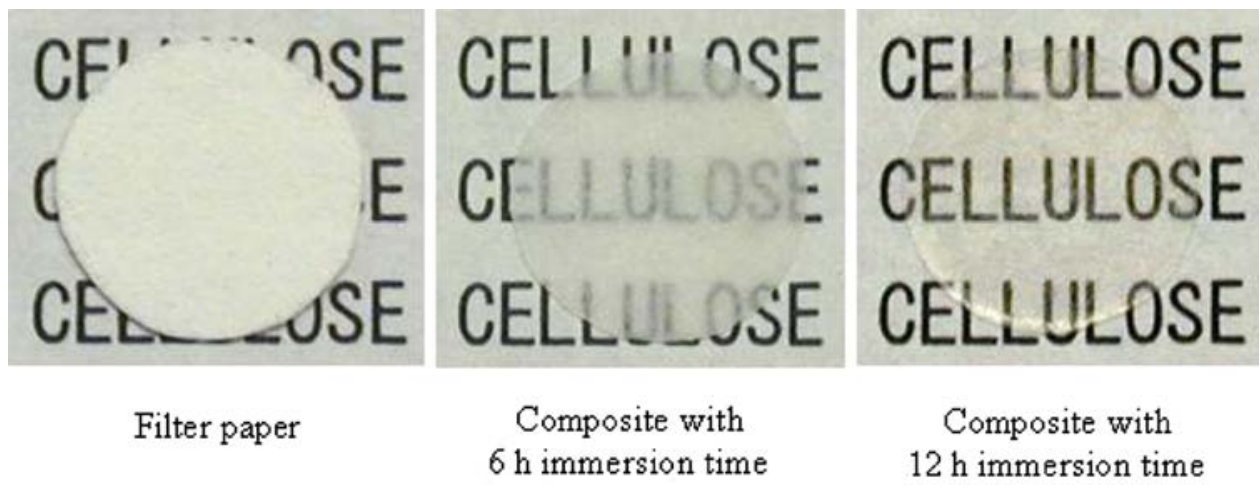

Fig. 31 Pictures of all-cellulose composites manufactured by selective dissolution of cellulose filter paper. The improvement in the composite's interface with increasing immersion time is evident through the observed improvement in optical transparency with immersion time for these all-cellulose composites [252]. Reproduction of images from [252] with permission from the American Chemical Society (ㄷ American Chemical Society 2007) far superior compared to traditional isotropic natural fibre mat composites based on flax/PP with typical tensile strengths of $50 \mathrm{MPa}[266,276]$. The improvement in the composite's interface with increasing immersion time was also evident through the observed improvement in optical transparency with immersion time [252] (Fig. 31).

$\mathrm{BC}$, on the other hand, has already a very strong network structure [21, 226, 277] based on high-modulus nano-size cellulose ribbons [23], which allows them to form more extensive hydrogen bonding (Fig. 32) [265, 278]. In the case of BC nanocomposites, only a slight enhancement in the network structure caused by the improved bonding from the newly created matrix is obtained. BC sheets have already a high initial level of inter-fibre bonding through extensive hydrogen bonding of the continuous nano-ribbons and no significant further improvements are observed with further dissolution times. These results are a further indication of the very strong initial hydrogen bonded
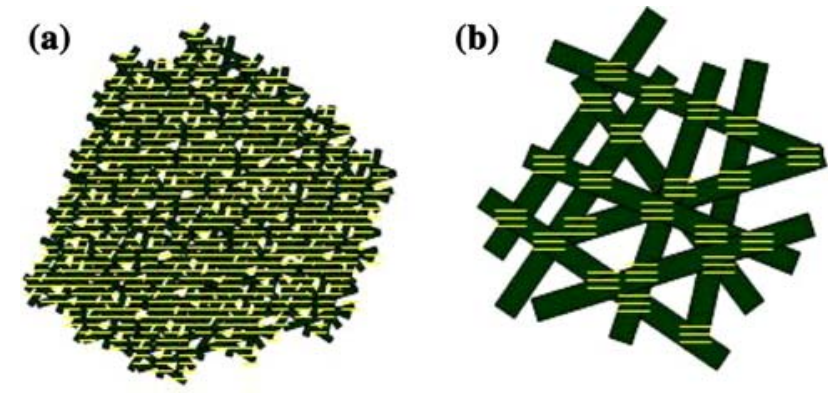

Fig. 32 Schematic illustration of extensive hydrogen bonding in a bacterial cellulose (nano-size network) compared to b cellulose paper (micro-size network) [265]. Reproduction of image from [265] with permission from Springer (ㄷ Springer 2009)

network that can be created by nano-size cellulose fibres such as in $\mathrm{BC}$, which do not require further strengthening through a cellulose matrix. 


\section{Discussion and conclusions}

It has been shown that cellulose nanofibres have an exciting potential as reinforcements in nanocomposites. They also, due to their size and the ability to chemically modify their surface, have great potential for a wide variety of applications; foams, adhesives, hierarchical materials and electronic display materials. A number of methods have been reviewed that enable cellulose nanofibres to be extracted from either plants or animal sources. It has to be remembered that in order to do this, some disruption of structure may occur, and so efforts to reduce damage during extraction are of paramount importance. It is also worth noting that mechanical means of fibre separation do require large amounts of energy, and so efforts to reduce this, either by enzymatic or chemical methods, will become increasingly important. The potential mechanical properties of cellulose nanofibres compete well with other engineering materials, and we have seen that this could be useful in high-end technological applications. We have seen how dispersion is also a critical step in the production of cellulose nanocomposites. Layer-by-layer deposition offers a facile route to overcoming this, with remarkable percolation of whiskers interacting with each other, and with the surrounding matrix, in a way that greatly enhances the mechanical properties of the resultant material. Cellulose nanowhiskers have a high surface area to volume ratio. This means that the surface plays a dominant role in not only the mechanical efficiency of stress transfer in a nanocomposite, but also the ability to modify the surface chemistry. We have seen that this can be used to "switchoff" the nanowhisker-nanowhisker interaction via a disruption of hydrogen bonding, which may also facilitate nanocomposite production. The high surface area can also be used as a template for polymerisation, which opens up the ability to make a highly reactive surface for a wide range of applications. By grafting DNA to the surface of cellulose nanowhiskers it should also be possible then to utilise self-assembly methods to generate new forms of composite biomaterials. The chemical coupling of chromophores to the surface of nanowhiskers has provided a route for following dispersion of cellulose nanowhiskers in nanocomposite materials, and TEMPO oxidation a means for isolating nanofibres. In addition to this, techniques such as Raman spectroscopy may provide a route for analysing, in a quantitative sense, the stress-transfer efficiency of cellulose nanofibres and polymeric resins, but also whisker-whisker interactions.

Other forms of cellulose nanofibres, such as BC, have been shown to be useful for generating hierarchical composites. This approach offers a way for long micrometresized fibres to be more effectively used in composites by enhancing coupling between the fibre surface and the surrounding resin. $\mathrm{BC}$ nanofibres have also been shown to be useful for generating optically transparent and flexible composite films with low thermal expansion coefficients. It has also been shown that by combining these high stiffness fibrils with a cellulose matrix, excellent mechanical properties can be obtained for what are now termed "all-cellulose" nanocomposites. Nanofibrous networks of cellulose, produced by mechanical means, can, through careful extraction, also be used for this application. The fibrils generated appear to replicate structures seen in the native primary wall of plant cells. In the form of nanopaper, the material has high toughness and can be combined effectively as a filler for foams. Incorporated with other polysaccharides, such as starch, there is a promising future for new light weight yet mechanically stable materials.

Acknowledgements Some of the authors wish to thank the following for allowing them to carry out their research. The EPSRC and the Malaysian government for financial support (S.J.E.). Financial support from DuPont (Young Professor Award to C.W.), the L. Stokes Cleveland VAMC Advanced Platform Technology Center (J.R.C.), an Ohio Innovation Incentive Fellowship (C.W., S.J.R., J.R.C.), the Department of Veteran's Affairs Associate Investigator Career Development Program (J.R.C.), and the National Institute of Health through Grant R21NS053798-01 (C.W., S.J.R., J.R.C.) is gratefully acknowledged. M.I.A. thanks the financial support of the Guggenheim Foundation. M.I.A. and N.E.M. also acknowledge the financial support from CONICET (National Research Council from Argentina) and ANPCyT (National Agency for the Promotion of Science and Technology, Argentina). M.I.A. and N.E.M. thank the collaboration of Prof. M.L. Auad (Auburn University, USA). T.P. would like to thank Prof. T. Nishino (Kobe University, Japan) for his collaboration on all-cellulose composites. A.B. wishes to thank the EPSRC for funding the research through a Challenging Engineering grant.

\section{References}

1. Klemm D, Heublein B, Fink HP, Bohn A (2005) Angew Chem Int Ed 44:3358

2. Favier V, Chanzy H, Cavaille JY (1995) Macromolecules 28:6365

3. Khadem HS (1988) Carbohydrate chemistry: monosaccharides and their oligomers. Academic Press Ltd., New York

4. Klemm D, Philipp B, Heinze T, Heinze U, Wagenknecht W (1998) Comprehensive cellulose chemistry. Wiley VCH, Chichester

5. Atalla RH, Vanderhart DL (1984) Science 223:283

6. Nishiyama Y, Langan P, Chanzy H (2002) J Am Chem Soc 124:9074

7. Nishiyama Y, Sugiyama J, Chanzy H, Langan P (2003) J Am Chem Soc 125:14300

8. Kroonbatenburg LMJ, Kroon J, Northolt MG (1986) Polym Commun 27:290

9. Meyer KH, Lotmar W (1936) Helv Chim Acta 19:68

10. Sakurada I, Nukushina Y, Ito T (1962) J Polym Sci 57:651

11. Nishino T, Takano K, Nakamae K (1995) J Polym Sci B 33:1647

12. Lyons WJ (1959) J Appl Phys 30:796

13. Treloar LRG (1960) Polymer 1:290 
14. Matsuo M, Sawatari C, Iwai Y, Ozaki F (1990) Macromolecules 23:3266

15. Tashiro K, Kobayashi M (1991) Polymer 32:1516

16. Marhofer RJ, Reiling S, Brickmann J (1996) Ber Bunsen-Ges Phys Chem Chem Phys 100:1350

17. Sturcova A, Davies GR, Eichhorn SJ (2005) Biomacromolecules 6:1055

18. Eichhorn SJ, Davies GR (2006) Cellulose 13:291

19. Diddens I, Murphy B, Krisch M, Muller M (2008) Macromolecules 41:9755

20. Kong K, Wilding MA, Ibbett RN, Eichhorn SJ (2008) Faraday Discuss 139:283

21. Iguchi M, Yamanaka S, Budhiono A (2000) J Mater Sci 35:261. doi:10.1023/A:1004775229149

22. Guhados G, Wan WK, Hutter JL (2005) Langmuir 21:6642

23. Hsieh Y-C, Yano H, Nogi M, Eichhorn SJ (2008) Cellulose 15:507

24. Bicerano J, Brewbaker JL (1995) J Chem Soc Faraday Trans 91:2507

25. Tajima K, Fujiwara M, Takai M, Hayashi J (1995) Mokuzai Gakkaishi 41:749

26. Yano H, Sugiyama J, Nakagaito AN, Nogi M, Matsuura T, Hikita M, Handa K (2005) Adv Mater 17:153

27. Juntaro J, Pommet M, Kalinka G, Mantalaris A, Shaffer MSP, Bismarck A (2008) Adv Mater 20:3122

28. Heng JYY, Pearse DF, Thielmann F, Lampke T, Bismarck A (2007) Compos Interfaces 14:581

29. Juntaro J, Pommet M, Mantalaris A, Shaffer M, Bismarck A (2007) Compos Interfaces 14:753

30. Pommet M, Juntaro J, Heng JYY, Mantalaris A, Lee AF, Wilson K, Kalinka G, Shaffer MSP, Bismarck A (2008) Biomacromolecules 9:1643

31. Turbak AF, Snyder FW, Sandberg KR (1983) J Appl Polym Sci Appl Polym Symp 37:815

32. Nakagaito AN, Yano H (2005) Appl Phys A 80:155

33. Svagan AJ, Samir M, Berglund LA (2007) Biomacromolecules $8: 2556$

34. Johnson RK, Zink-Sharp A, Renneckar SH, Glasser WG (2009) Cellulose 16:227

35. Ranby BG, Noe RW (1961) J Polym Sci 51:337

36. Revol JF, Bradford H, Giasson J, Marchessault RH, Gray DG (1992) Int J Biol Macromol 14:170

37. Ranby BG (1952) Arkiv for Kemi 4:241

38. Rusli R, Eichhorn SJ (2008) Appl Phys Lett 93:033111

39. Hull D, Clyne TW (1996) An introduction to composite materials. Cambridge University Press, Cambridge

40. Halpin JC, Kardos JL (1976) Polym Eng Sci 16:344

41. Van Es M (2001) Polymer-clay nanocomposites-the importance of particle dimensions, PhD thesis, TU Delft

42. Davies GC, Bruce DM (1998) Text Res J 68:623

43. Samir M, Alloin F, Dufresne A (2005) Biomacromolecules 6:612

44. Kamel S (2007) Express Polym Lett 1:546

45. Kvien I, Tanem BS, Oksman K (2005) Biomacromolecules 6:3160

46. Angles MN, Dufresne A (2000) Macromolecules 33:8344

47. Fleming K, Gray D, Prasannan S, Matthews S (2000) J Am Chem Soc 122:5224

48. Habibi Y, Goffin AL, Schiltz N, Duquesne E, Dubois P, Dufresne A (2008) J Mater Chem 18:5002

49. Siqueira G, Bras J, Dufresne A (2009) Biomacromolecules 10:425

50. Helbert W, Cavaille JY, Dufresne A (1996) Polym Compos 17:604

51. Grunert M, Winter WT (2002) J Polym Environ 10:27

52. Samir M, Alloin F, Paillet M, Dufresne A (2004) Macromolecules $37: 4313$
53. Henriksson M, Henriksson G, Berglund LA, Lindstrom T (2007) Eur Polym J 43:3434

54. Mathew AP, Dufresne A (2002) Biomacromolecules 3:609

55. Orts WJ, Shey J, Imam SH, Glenn GM, Guttman ME, Revol JF (2005) J Polym Environ 13:301

56. Kvien I, Sugiyama J, Votrubec M, Oksman K (2007) J Mater Sci 42:8163. doi:10.1007/s10853-007-1699-2

57. Samir M, Alloin F, Sanchez JY, Dufresne A (2004) Polymer 45:4149

58. Samir M, Alloin F, Gorecki W, Sanchez JY, Dufresne A (2004) J Phys Chem B 108:10845

59. Samir M, Mateos AM, Alloin F, Sanchez JY, Dufresne A (2004) Electrochim Acta 49:4667

60. Samir M, Chazeau L, Alloin F, Cavaille JY, Dufresne A, Sanchez JY (2005) Electrochim Acta 50:3897

61. Samir M, Alloin F, Dufresne A (2006) Compos Interfaces 13:545

62. Zimmermann T, Pohler E, Geiger T (2004) Adv Eng Mater 6:754

63. Zimmermann T, Pohler E, Schwaller P (2005) Adv Eng Mater $7: 1156$

64. Choi YJ, Simonsen J (2006) J Nanosci Nanotechnol 6:633

65. Favier V, Canova GR, Cavaille JY, Chanzy H, Dufresne A, Gauthier C (1995) Polym Adv Technol 6:351

66. Dufresne A, Cavaille JY, Helbert W (1997) Polym Compos $18: 198$

67. Dubief D, Samain E, Dufresne A (1999) Macromolecules 32:5765

68. Dufresne A, Kellerhals MB, Witholt B (1999) Macromolecules 32:7396

69. Dufresne A (2000) Compos Interfaces 7:53

70. Chazeau L, Cavaille JY, Canova G, Dendievel R, Boutherin B (1999) J Appl Polym Sci 71:1797

71. Chazeau L, Cavaille JY, Terech P (1999) Polymer 40:5333

72. Chazeau L, Paillet M, Cavaille JY (1999) J Polym Sci B 37:2151

73. Chazeau L, Cavaille JY, Perez J (2000) J Polym Sci B $38: 383$

74. Ruiz MM, Cavaille JY, Dufresne A, Graillat C, Gerard JF (1999) Eurofillers '99 conference. Wiley-VCH Verlag Gmbh, Lyon, France, p 211

75. de Rodriguez NLG, Thielemans W, Dufresne A (2006) Cellulose 13:261

76. Heux L, Chauve G, Bonini C (2000) Langmuir 16:8210

77. Gousse C, Chanzy H, Excoffier G, Soubeyrand L, Fleury E (2002) Polymer 43:2645

78. Nair KG, Dufresne A, Gandini A, Belgacem MN (2003) Biomacromolecules 4:1835

79. Angellier H, Molina-Boisseau S, Belgacem MN, Dufresne A (2005) Langmuir 21:2425

80. Labet M, Thielemans W, Dufresne A (2007) Biomacromolecules 8:2916

81. Habibi Y, Dufresne A (2008) Biomacromolecules 9:1974

82. Yi J, Xu QX, Zhang XF, Zhang HL (2008) Polymer 49:4406

83. Morandi G, Heath L, Thielemans W (2009) Langmuir 25: 8280

84. Lönnberg H, Fogelström L, Berglund L, Malmström E, Hult A (2008) Eur Polym J 44:2991

85. Samir M, Alloin F, Sanchez JY, El Kissi N, Dufresne A (2004) Macromolecules 37:1386

86. Marcovich NE, Auad ML, Bellesi NE, Nutt SR, Aranguren MI (2006) J Mater Res 21:870

87. van den Berg O, Capadona JR, Weder C (2007) Biomacromolecules 8:1353

88. Nakagaito AN, Yano H (2004) Appl Phys A 78:547

89. Nakagaito AN, Yano H (2008) Cellulose 15:555 
90. Shimazaki Y, Miyazaki Y, Takezawa Y, Nogi M, Abe K, Ifuku S, Yano H (2007) Biomacromolecules 8:2976

91. Nogi M, Handa K, Nakagaito AN, Yano H (2005) Appl Phys Lett $87: 3$

92. Iwamoto S, Abe K, Yano H (2008) Biomacromolecules 9:1022 93. Henriksson M, Berglund LA (2007) J Appl Polym Sci 106:2817

94. Oksman K, Mathew AP, Bondeson D, Kvien I (2006) Compos Sci Technol 66:2776

95. Bondeson D, Oksman K (2007) Compos A 38:2486

96. Dong XM, Revol JF, Gray DG (1998) Cellulose 5:19

97. Ebeling T, Paillet M, Borsali R, Diat O, Dufresne A, Cavaille JY, Chanzy H (1999) Langmuir 15:6123

98. Dufresne A, Dupeyre D, Vignon MR (2000) J Appl Polym Sci 76:2080

99. Favier V, Canova GR, Shrivastava SC, Cavaille JY (1997) Polym Eng Sci 37:1732

100. Hajji P, Cavaille JY, Favier V, Gauthier C, Vigier G (1996) Polym Compos 17:612

101. Dufresne A, Vignon MR (1998) Macromolecules 31:2693

102. Wu QJ, Henriksson M, Liu X, Berglund LA (2007) Biomacromolecules 8:3687

103. Li FK, Zhang X, Hou JN, Xu M, Lu XL, Ma DZ, Kim BK (1997) J Appl Polym Sci 64:1511

104. Auad ML, Richardson T, Mosiewicki MA, Marcovich NE, Aranguren MI (2008) Reinforcement of segmented polyurethanes with cellulose crystals. In: XI Simposio Latinoamericano y IX Congreso Iberoamericano de Polymerios, Slap 2008, Peru

105. Auad ML, Contos VS, Nutt S, Aranguren MI, Marcovich NE (2008) Polym Int 57:651

106. Mitra VK, Risen WM, Baughman RH (1977) J Chem Phys $66: 2731$

107. Galiotis C, Robinson IM, Young RJ, Smith BJE, Batchelder DN (1985) Polym Commun 26:354

108. Galiotis C, Young RJ, Yeung PHJ, Batchelder DN (1984) J Mater Sci 19:3640. doi:10.1007/BF00552276

109. Young RJ, Eichhorn SJ (2007) Polymer 48:2

110. Hamad WY, Eichhorn S (1997) J Eng Mater Technol Trans ASME 119:309

111. Eichhorn SJ, Hughes M, Snell R, Mott L (2000) J Mater Sci Lett 19:721

112. Eichhorn SJ, Sirichaisit J, Young RJ (2001) J Mater Sci 36:3129. doi:10.1023/A:1017969916020

113. Eichhorn SJ, Young RJ (2003) Compos Sci Technol 63:1225

114. Eichhorn SJ, Young RJ (2004) Compos Sci Technol 64:767

115. Tze WTY, Gardner DJ, Tripp CP, O’Neill SC (2006) J Adhesion Sci Technol 20:1649

116. Tze WTY, O’Neill SC, Tripp CP, Gardner DJ, Shaler SM (2007) Wood Fiber Sci 39:184

117. Gierlinger N, Schwanninger M, Reinecke A, Burgert I (2006) Biomacromolecules 7:2077

118. Peetla P, Schenzel KC, Diepenbrock W (2006) Appl Spectrosc 60:682

119. Wiley JH, Atalla RH (1987) Carbohydr Res 160:113

120. Edwards HGM, Farwell DW, Webster D (1997) Spectrochim Acta A 53:2383

121. Krenchel H (1964) Fibre reinforcement. Academisk Forlag, Copenhagen

122. Iwamoto S, Kai W, Isogai A, Iwata T (2009) Biomacromolecules 10:2571

123. Lima MMD, Borsali R (2004) Macromol Rapid Commun 25:771

124. Schroers M, Kokil A, Weder C (2004) J Appl Polym Sci 93:2883

125. Ljungberg N, Bonini C, Bortolussi F, Boisson C, Heux L, Cavaille JY (2005) Biomacromolecules 6:2732
126. Bonini C, Heux L, Cavaille JY, Lindner P, Dewhurst C, Terech P (2002) Langmuir 18:3311

127. Araki J, Wada M, Kuga S (2001) Langmuir 17:21

128. Yuan HH, Nishiyama Y, Wada M, Kuga S (2006) Biomacromolecules 7:696

129. Marchessault RH, Morehead FF, Walter NM (1959) Nature 184:632

130. Turbak A, Snyder F, Sandberg K (1983) Suspensions containing microfibrillated cellulose, edited by U.P. Office, USA

131. Viet D, Beck-Candanedo S, Gray DG (2007) Cellulose 14:109

132. Araki J, Wada M, Kuga S, Okano T (1998) Colloid Surf A $142: 75$

133. Araki J, Wada M, Kuga S, Okano T (2000) Langmuir 16:2413

134. van den Berg O, Schroeter M, Capadona JR, Weder C (2007) J Mater Chem 17:2746

135. Capadona JR, Van Den Berg O, Capadona LA, Schroeter M, Rowan SJ, Tyler DJ, Weder C (2007) Nat Nanotechnol 2:765

136. Takayanagi M, Minami S, Uemura S (1964) J Polym Sci C 113

137. Ouali N, Cavaille JY, Perez J (1990) 3rd European symposium on polymer blends, Cambridge, UK, p 55

138. Capadona JR, Shanmuganathan K, Triftschuh S, Seidel S, Rowan SJ, Weder C (2009) Biomacromolecules 10:712

139. Capadona JR, Shanmuganathan K, Tyler DJ, Rowan SJ, Weder C (2008) Science 319:1370

140. Trotter JA, Tipper J, Lyons-Levy G, Chino K, Heuer AH, Liu Z, Mrksich M, Hodneland C, Dillmore WS, Koob TJ, KoobEmunds MM, Kadler K, Holmes D (2000) Colloquium on biotechnology of extracellular matrix. Portland Press, Leeds, p 357

141. Trotter JA, Lyons-Levy G, Chino K, Koob TJ, Keene DR, Atkinson MAL (1999) Matrix Biol 18:569

142. Szulgit GK, Shadwick RE (2000) J Exp Biol 203:1539

143. Alberts B, Bray D, Lewis J, Raff M, Roberts K, Watson JD (1994) Molecular biology of the cell. Garland Publishing Inc., New York

144. Bellamkonda RV (2008) Nat Mater 7:347

145. Craig SL (2008) Angew Chem Int Ed 47:8776

146. Lonnberg H, Zhou Q, Brumer H, Teeri TT, Malmstrom E, Hult A (2006) Biomacromolecules 7:2178

147. Lindqvist J, Nystrom D, Ostmark E, Antoni P, Carlmark A, Johansson M, Hult A, Malmstrom E (2008) Biomacromolecules 9:2139

148. Westlund R, Carlmark A, Hult A, Malmstrom E, Saez IM (2007) Soft Matter 3:866

149. Lindqvist J, Malmstrom E (2006) J Appl Polym Sci 100:4155

150. Plackett D, Jankova K, Egsgaard H, Hvilsted S (2005) Biomacromolecules 6:2474

151. Singh N, Chen Z, Tomer N, Wickramasinghe SR, Soice N, Husson SM (2008) J Membr Sci 311:225

152. Roy D, Guthrie JT, Perrier S (2005) Macromolecules 38:10363

153. Roy D, Knapp JS, Guthrie JT, Perrier S (2008) Biomacromolecules 9:91

154. Barsbay M, Guven O, Davis TP, Barner-Kowollik C, Barner L (2009) Polymer 50:973

155. Harrisson S, Malmstrom E, Hult A, Hawker CJ, Wooley KL (2004) 228th national meeting of the American Chemical Society. American Chemical Society, Philadelphia, PA, p 578

156. Zoppe J, Habibi Y, Rojas OJ (2008) Abstracts of papers, 235th ACS national meeting, New Orleans, LA, April 6-10, 2008, CELL

157. Morandi G, Thielemans W (2008) Abstracts of papers, 236th ACS national meeting, Philadelphia, PA, August 17-21, 2008, POLY

158. Labet M, Thielemans W (2009) 13th international IUPAC conference on polymers \& organic chemistry, IUPAC, Montreal, Canada, 2009 
159. Morandi G, Thielemans W (2009) 13th international IUPAC conference on polymers \& organic chemistry, Montreal, Canada, 2009

160. Xu QX, Yi J, Zhang XF, Zhang HL (2008) Eur Polym J 44:2830

161. Dong S, Roman M (2007) J Am Chem Soc 129:13810

162. Aloisi GG, Costantino U, Latterini L, Nocchetti M, Camino G, Frache A (2006) J Phys Chem Solids 67:909

163. Langat J, Bellayer S, Hudrlik P, Hudrlik A, Maupin PH, Gilman JW, Raghavan D (2006) Polymer 47:6698

164. Beck-Candanedo S, Roman M, Gray DG (2005) Biomacromolecules 6:1048

165. Elazzouzi-Hafraoui S, Nishiyama Y, Putaux J-L, Heux L, Dubreuil F, Rochas C (2008) Biomacromolecules 9:57

166. Herrick FW, Casebier RL, Hamilton JK, Sandberg KR (1983) J Appl Polym Sci Appl Polym Symp 37:797

167. Turbak AF, Snyder FW, Sandberg KR (1983) J Appl Polym Sci Appl Polym Symp 37:815

168. Paakko M, Ankerfors M, Kosonen H, Nykanen A, Ahola S, Osterberg M, Ruokolainen J, Laine J, Larsson PT, Ikkala O, Lindstrom T (2007) Biomacromolecules 8:1934

169. Wagberg L, Decher G, Norgren M, Lindstrom T, Ankerfors M, Axnas K (2008) Langmuir 24:784

170. Saito T, Kimura S, Nishiyama Y, Isogai A (2007) Biomacromolecules 8:2485

171. Saito T, Isogai A (2006) Colloid Surf A 289:219

172. Saito T, Isogai A (2004) Cellulose Commun 11:192

173. Saito T, Nishiyama Y, Putaux J-L, Vignon M, Isogai A (2006) Biomacromolecules 7:1687

174. Johnson RK, Zink-Sharp A, Renneckar SH, Glasser WG (2009) Cellulose (Dordrecht, Netherlands) 16:227

175. Li Q, Renneckar S (2009) Cellulose (in press)

176. Dunky M, Pizzi T, Van Leemput M (2002) State of the art, Report, COST action E13, Wood adhesion and glued products

177. Bishopp JA (1991) Annual conference on adhesion and adhesives. Butterworth-Heinemann Ltd., London, p 178

178. Guthrie J (2005) In: Packham DE (ed) Handbook of adhesion. Wiley, Chichester, p 638

179. Hunston DL, Bitner JL, Rushford JL, Oroshnik J, Rose WS (1980) J Elastomer Plast 12:133

180. Kinloch AJ (2003) MRS Bull 28:445

181. Kinloch AJ, Lee JH, Taylor AC, Sprenger S, Eger C, Egan D (2003) J Adhesion 79:867

182. Soares BG, Goncalez V, Galimberti R, Sirqueira AS, Barcia FL, Simao RA (2008) J Appl Polym Sci 108:159

183. Stewart I, Chambers A, Gordon T (2007) Int J Adhesion Adhes 27:277

184. Tzetzis D, Hogg PJ (2006) Compos Part A 37:1239

185. Serrano E, Gustafsson PJ (1999) Int J Adhesion Adhes 19:9

186. Serrano E (2004) Int J Adhesion Adhes 24:23

187. Konnerth J, Gindl W, Harm M, Muller U (2006) Holz Als RohUnd Werkstoff 64:269

188. Konnerth J, Jager A, Eberhardsteiner J, Muller U, Gindl W (2006) J Appl Polym Sci 102:1234

189. Konnerth J, Gindl W, Muller U (2007) J Appl Polym Sci 103:3936

190. Adhesives for load-bearing timber structures, British-adopted European standard, EN302 parts 1-4 (2004)

191. Nogi M, Handa K, Nakagaito AN, Yano H (2005) Appl Phys Lett 87:243110

192. Nogi M, Abe K, Handa K, Nakatsubo F, Ifuku S, Yano H (2006) Appl Phys Lett 89:133124

193. Nogi M, Yano H (2008) Adv Mater 20:1849

194. Nogi M, Abe K, Handa K, Nakatsubo F, Ifuku S, Yano H (2006) Appl Phys Lett 89:233123

195. Ifuku S, Nogi M, Abe K, Handa K, Nakatsubo F, Yano H (2007) Biomacromolecules 8:1973
196. Iwamoto S, Nakagaito AN, Yano H, Nogi M (2005) Appl Phys A 81:CP8

197. Iwamoto S, Nakagaito AN, Yano H (2007) Appl Phys A 89:461

198. Abe K, Iwamoto S, Yano H (2007) Biomacromolecules 8:3276

199. Nogi M, Iwamoto S, Nakagaito AN, Yano H (2009) Adv Mater 21:1595

200. Yano H, Hirose A, Inaba S (1997) J Mater Sci Lett 16:1906

201. Yano H, Hirose A, Collins PJ, Yazaki Y (2001) J Mater Sci Lett 20:1125

202. Yano H (2001) J Mater Sci Lett 20:1127

203. Yano H, Nakahara S (2004) J Mater Sci 39:1635. doi: 10.1023/B:JMSC.0000016162.43897.0a

204. Nakagaito AN, Iwamoto S, Yano H (2005) Appl Phys A 80:93

205. Nakagaito AN, Yano H (2008) Cellulose 15:323

206. Gomes A, Goda K, Ohgi J (2004) JSME Int J A 47:541

207. Goda K, Sreekala MS, Gomes A, Kaji T, Ohgi J (2006) Compos A 37:2213

208. Ishikura Y, Nakano T (2007) J Wood Sci 53:175

209. Nakano T, Sugiyama J, Norimoto M (2000) Holzforschung $54: 315$

210. Iwatake A, Nogi M, Yano H (2008) Compos Sci Technol 68:2103

211. Dalmas F, Chazeau L, Gauthier C, Cavaille JY, Dendievel R (2006) Polymer 47:2802

212. Dalmas F, Cavaille JY, Gauthier C, Chazeau L, Dendievel R (2007) Compos Sci Technol 67:829

213. Angles MN, Dufresne A (2001) Macromolecules 34:2921

214. Suryanegara L, Nakagaito AN, Yano H (2009) Compos Sci Technol 69:1187

215. Nakagaito AN, Fujimura A, Sakai T, Hama Y, Yano H (2009) Compos Sci Technol 69:1293

216. Kong J, Franklin NR, Zhou C, Chapline MG, Peng S, Cho K, Dail H (2000) Science 287:622

217. Bachtold A, Hadley P, Nakanishi T, Dekker C (2001) Science 294:1317

218. Zimmermann J, Cebulla MPJ, Monninghoff S, Kiedrowski GV (2008) Angew Chem Int Ed 47:1

219. Mangalam AP, Simonsen J, Benight AS (2009) Biomacromolecules 10:497

220. Lloyd RD, Burns MC (1979) J Polym Sci 17:3473

221. Williams A, Ibrahim IT (1981) Chem Rev 81:589

222. Winter WT, Goodrich JD (2005) Abstracts of papers, 229th ACS national meeting, San Diego, CA, March 13-17, 2005, CELL

223. Lehninger A (1970) Biochemistry. Worth Publishers, New York

224. Mohanty AK, Misra M, Hinrichsen G (2000) Macromol Mater Eng 276:1

225. Bismarck A, Mishra S, Lampke T (2005) In: Mohanty AK, Misra M, Drzal LT (eds) Natural fibres, biopolymers and their biocomposites. CRC Press, Boca Raton, p 261

226. Yamanaka S, Watanabe K, Kitamura N, Iguchi M, Mitsuhashi S, Nishi Y, Uryu M (1989) J Mater Sci 24:3141. doi:10.1007/ BF01139032

227. Bismarck A (2008) Express Polym Lett 2:687

228. Gardner DJ, Oporto GS, Mills R, Samir M (2008) J Adhesion Sci Technol 22:545

229. Baltazar-Y-Jimenez A, Bistritz M, Schulz E, Bismarck A (2008) Compos Sci Technol 68:215

230. Hsiao KT (2006) In: Advani SG (ed) Processing and properties of nanocomposites. World Scientific, New Jersey, p 141

231. Juntaro J (2008) Environmentally friendly truly green hierarchical nanocomposites. Imperial College, London

232. Paakko M, Vapaavuori J, Silvennoinen R, Kosonen $H$, Ankerfors M, Lindstrom T, Berglund LA, Ikkala O (2008) Soft Matter 4:2492 
233. Henriksson M, Berglund LA, Isaksson P, Lindstrom T, Nishino $\mathrm{T}$ (2008) Biomacromolecules 9:1579

234. Svagan AJ, Hedenqvist MS, Berglund L (2009) Compos Sci Technol 69:500

235. Ward IM, Hine PJ (1997) Polym Eng Sci 37:1809

236. Ward IM, Hine PJ (2004) Polymer 45:1413

237. Cabrera N, Alcock B, Loos J, Peijs T (2004) Proc Inst Mech Eng L 218:145

238. Alcock B, Cabrera NO, Barkoula NM, Loos J, Peijs T (2006) Compos A 37:716

239. Alcock B, Cabrera NO, Barkoula NM, Spoelstra AB, Loos J, Peijs T (2007) Compos A 38:147

240. Alcock B, Cabrera NO, Barkoula NM, Peijs T (2006) Compos Sci Technol 66:1724

241. Alcock B, Cabrera NO, Barkoula NM, Reynolds CT, Govaert LE, Peijs T (2007) Compos Sci Technol 67:2061

242. Nishino T, Matsuda I, Hirao K (2004) Macromolecules 37:7683

243. Qin C, Soykeabkaew N, Xiuyuan N, Peijs T (2008) Carbohydr Polym 71:458

244. Zhao Q, Yam R, Zhang BQ, Yang YK, Cheng XJ, Li R (2009) Cellulose 16:217

245. Gindl W, Keckes J (2004) Compos Sci Technol 64:2407

246. Peijs T (2003) Mater Today 30

247. Cabrera N, Alcock B, Loos J, Peijs T (2004) Proc Inst Mech Eng L 218:145

248. Alcock B, Cabrera NO, Barkoula N-M, Peijs T (2006) Compos A 37(5):716

249. Alcock B, Cabrera NO, Barkoula N-M, Spoelstra AB, Loos J, Peijs T (2007) Compos A 38:147

250. Matsumura H, Sugiyama J, Glasser WG (2000) J Appl Polym Sci 78:2242

251. Matsumura H, Glasser WG (2000) J Appl Polym Sci 78:2254

252. Nishino T, Arimoto N (2007) Biomacromolecules 8:2712

253. Gandini A, Curvelo AAD, Pasquini D, de Menezes AJ (2005) Polymer 46:10611

254. de Menezes AJ, Pasquini D, Curvelo AAD, Gandini A (2009) Carbohydr Polym 76:437

255. de Menezes AJ, Pasquini D, Curvelo AAD, Gandini A (2009) Cellulose 16:239

256. Gindl W, Keckes J (2005) Polymer 46:10221

257. Gindl W, Martinschitz KJ, Boesecke P, Keckes J (2006) Compos Sci Technol 66:2639
258. Gindl W, Keckes J (2007) J Appl Polym Sci 103:2703

259. Duchemin B, Newman RH, Staiger MP (2007) Cellulose 14:311

260. Duchemin BJC, Newman RH, Staiger MP (2009) Compos Sci Technol 69:1225

261. Xun L, Ming QZ, Min ZR, Gui CY (2003) Polym Adv Technol $14: 676$

262. Lu X, Zhang MQ, Rong MZ, Yue DL, Yang GC (2004) Polym Polym Compos 12:297

263. Soykeabkaew N, Arimoto N, Nishino T, Peijs T (2008) Compos Sci Technol 68:2201

264. Soykeabkaew N, Nishino T, Peijs T (2009) Compos A 40:321

265. Soykeabkaew N, Sian C, Gea S, Nishino T, Peijs T (2009) Cellulose 16:435

266. Heijenrath R, Peijs T (1996) Adv Compos Lett 5:81

267. Luo S, Netravali AN (1999) Polym Compos 20:367

268. Van Den Oever MJA, Bos HL, Van Kemenade MJJM (2000) Appl Compos Mater 7:387

269. Oksman K, Wallstrom L, Berglund LA, Filho RDT (2002) J Appl Polym Sci 84:2358

270. Madsen B, Lilholt H (2003) Compos Sci Technol 63:1265

271. Liu W, Misra M, Askeland P, Drzala LT, Mohanty AK (2005) Polymer 46:2710

272. Van de Weyenberg I, Truong TC, Vangrimde B, Verpoest I (2006) Compos A 37:1368

273. Brahim SM, Cheikh RB (2007) Compos Sci Technol 67:140

274. Klemm D, Schmauder H, Heinze T (2003) Biopolymers 6:275

275. Lu X, Zhang MQ, Rong MZ, Shi G, Yang GC (2003) Compos Sci Technol 63:177

276. Garkhail SK, Heijenrath RWH, Peijs T (2000) Appl Compos Mater 7:351

277. Gea S, Torres FG, Troncoso OP, Reynolds CT, Vilasecca F, Iguchi M, Peijs T (2007) Int Polym Process 22:497

278. Van de Weyenberg I, Ivens J, De Coster A, Kino B, Baetens E, Verpoest I (2001) 1st international EcoComp conference. Elsevier Sci Ltd., London, p 1241

279. Ashby MF, Jones DRH (1989) Engineering materials 1: an introduction to their properties and applications. Pergamon Press, Oxford

280. Morton WE, Hearle JWS (1975) Physical properties of textile fibres. William Heinemann Ltd, London 